\title{
Sensory Systems and Environmental Change on Behavior during Social Interactions
}

\author{
S. M. Bierbower, ${ }^{1}$ J. Nadolski, ${ }^{2}$ and R. L. Cooper ${ }^{1}$ \\ ${ }^{1}$ Department of Biology \& Center for Muscle Biology, University of Kentucky, Lexington, KY 40506-0225, USA \\ ${ }^{2}$ Department of Mathematical and Computational Sciences, Benedictine University, Lisle, IL 60532, USA
}

Correspondence should be addressed to R. L. Cooper; rlcoop1@email.uky.edu

Received 21 December 2012; Revised 13 March 2013; Accepted 15 March 2013

Academic Editor: Randy J. Nelson

Copyright (C) 2013 S. M. Bierbower et al. This is an open access article distributed under the Creative Commons Attribution License, which permits unrestricted use, distribution, and reproduction in any medium, provided the original work is properly cited.

\begin{abstract}
The impact of environmental conditions for transmitting sensory cues and the ability of crayfish to utilize olfaction and vision were examined in regards to social interactive behavior. The duration and intensity of interactions were examined for conspecific crayfish with different sensory abilities. Normally, vision and chemosensory have roles in agonistic communication of Procambarus clarkii; however, for the blind cave crayfish (Orconectes australis packardi), that lack visual capabilities, olfaction is assumed to be the primary sensory modality. To test this, we paired conspecifics in water and out of water in the presence and absence of white light to examine interactive behaviors when these various sensory modalities are altered. For sighted crayfish, in white light, interactions occurred and escalated; however, when the water was removed, interactions and aggressiveness decreased, but, there was an increase in visual displays out of the water. The loss of olfaction abilities for blind cave and sighted crayfish produced fewer social interactions. The importance of environmental conditions is illustrated for social interactions among sighted and blind crayfish. Importantly, this study shows the relevance in the ecological arena in nature for species survival and how environmental changes disrupt innate behaviors.
\end{abstract}

\section{Introduction}

Social relationships may take many forms when organisms live in a group, and often times, the individuals must determine their status within a social structure [1-3]. Social dominance is a form of a social relationship in which individuals aggressively interact repeatedly. The interaction between individuals is a well-studied sequential series of interactions, with each individual having the option of terminating or continuing the interaction/contest at any time. The consequence of these interactions most likely results in a dominant individual who repeatedly wins encounters against a subordinate [3]. Therefore, agonistic encounters will generally establish social hierarchies between individuals in a population [4-9]. Dominance hierarchies are known to decrease aggressive interactions between individuals based upon social status, therefore stabilizing the population over time $[10,11]$

Smith [12] suggests that rank may be a strategy individuals adopt to maximize fitness in the population based upon the role of other individuals. This correlates with the established Barnard and Sibly [13] producer-scrounger game in which mixes of strategies work better than all one or the other of a specific strategy. There are obvious ecological benefits for being the dominant individual and little point in interacting if there is an absence of benefits with aggressive interactions. Thus, the benefit of interactions must account not only for the resource, but also the cost in obtaining the resource. The dominate individuals often have increased access to resources such as mates, food, and shelters [14, 15]. However, this may not always be the case since many other factors play a role such as the value of the resource [16], the inability to monopolize a resource [17], and the loss of resources' due to stealing of stores/caches by other individuals [18]. Furthermore, females with young often rise in the social ranks to better provide for their young [19], as well as hungry subordinate individuals often win encounters against dominants for access to food [20,21].

There are many factors involved in the establishment of social dominance, and it is well documented that environmental cues play a major role in the outcome of social interactions whether through chemosensory (odors, $[22,23]$ ), visual 
(opponent posturing, [24, 25]), and/or tactile cues (physical combat, $[4,5,7,8])$.

An ideal model system to study social interactions is with crayfish since typical interactions have been well documented for decades. Crayfish are known to form social hierarchies after very aggressive interactions $[4-9,26,27]$. Typically, the encounters escalate from visual threats of defense posturing to actual physical confrontations that include cheliped grasping and more aggressive behaviors where one will try to dismember or even kill another individual.

Currently, most studies observing social interactions occur in a natural field site or a location that mimics the typical environment. While this gives insights into typical behaviors, little is known of the interaction dynamics when natural changes occur such as when an organism leaves the aquatic environment or when sensory systems are diminished. Crayfish leave the water for various reasons such as to find food, mates, or when excessive competition may drive them to look for other niches. The environmental change with the absence of water would eliminate the typical escape response (i.e., tail flip) which allows for a fast retreat from conspecifics. In addition, the absence of water results in other factors influencing social interactions, such as a higher energy demand for movement mainly due to the lack of buoyancy, a greater probability of injury due to a slower response in movement, as well as retreat and also the lack of assessment through chemical cues of not only conspecifics, but also the environment in general. Thus, an organism is at greater risk since they lack the ability to assess their opponent and/or locate a safe place for retreat. This is especially true for a species evolutionarily lacking a sensory modality. Hence, it is of interest to examine the effect of diminished visual and olfactory/chemosensory sensory system. This is possible through studies in the absence of white light and the removal of the primary chemosensory appendage (i.e., antennules) in surface species, as well as studies in an evolutionarily distinct species of crayfish which lack the visual sensory modality.

Although vision and tactile have been suggested to be very important in social interactions for mediating the transfer of information, the full understanding on the ways these two sensory cues are used in agonistic communication remains unclear. It has been well studied and shown that vision is important for agonistic communication in other decapod species, such as fiddler crabs [28-30], hermit crabs [31-35], lobsters [36], and mantis shrimp [37]. Due to this obvious factor in so many other decapod crustaceans, we assume that the visual sensory cue would also be very important for information exchange among crayfish. We chose to separate the roles of vision and chemosensory in the agonistic communication of $P$. clarkii by conducting experiments in red light (not visible to $P$. clarkii) as well as removing the antennules, both independently and additively to a red light environment. The study of vision in this species is particularly appropriate, given that $P$. clarkii are normally active under a wide range of environmental light levels, and we mimic periods of dusk and dawn which are known to be particularly active time points [38].

Blind cave crayfish (Orconectes australis packardi) lack visual capabilities; therefore, they provide the opportunity to examine whether behavioral, morphological, and/or physiological evolutionary adaptations may have evolved uniquely to their species based upon the cave environment. Since cave crayfish have a reduced optic system and have more olfactory projection neurons than surface sighted crayfish, it was suggested they have more neural processing related to olfaction [39]. Cave crayfish appear to rely primarily on olfactory and tactile modalities, while surface crayfish rely primarily on visual and olfactory to assess and monitor their surroundings. Since these cave crayfish do have caudal photoreceptors in their 6th abdominal ganglion and respond to white light, studies were performed in white and red lights. The caudal photoreceptors are not sensitive to the red light used, as assayed in behavioral studies [40]. In accordance with the above information, it is logical that cave crayfish do not show the typical postural behaviors (visual display) identified in social encounters within their natural cave environment. We hypothesized that such displays would not be beneficial since conspecifics are not able to observe the visual display. While studies have addressed the neural structure of the optic systems [39] and the effects of light on social interactions [40], the typical behaviors of cave crayfish have not been as thoroughly studied as with surface crayfish. Currently, little is known of interaction dynamics in the absence of water which eliminates the typical escape response (i.e., tail flip) and/or with diminished chemosensory systems in either species of crayfish.

Chemical signals are also important sources of information in aquatic environments where visibility maybe limited when compared to terrestrial open environments [40]. Crayfish are known to have a [41, 42] well-developed olfactory system, and studies have shown that chemical signals play an important role in many aspects of their life $[23,43,44]$. Specifically in agonistic encounters, chemical signals appear to be more important than other offensive displays and signals for settling a fight [45]. Interestingly, research has shown that some species are able to recognize individuals that they have encountered in the recent past such as two species of hermit crabs [46-48], crab [49], mantis shrimp Gonodactylus festae [50, 51], lobsters Homarus americanus [52], and crayfish [53]. It has been shown that the individual recognition is based upon chemical signals that are emitted during social interactions [54-56] in crustaceans [57]. The chemical signals are important in maintaining the stable dominance hierarchies.

Chemical cues are known to be involved in the establishment of social hierarchies and are known to impact behavior $[58,59]$. Bovbjerg [5] first suggested that both vision and tactile are involved in the establishment of social hierarchies, and he also demonstrated that antennae are important for tactile orientation. The antennule is considered the organ most specialized for chemosensory detection and plays a leading role in tracking odor plumes [60] and individual recognition [61]. One way to address the influence of sensory cues is to remove important sensory systems individually and simultaneously. Specifically, by removing the antennules and vision through the absence of white light (provide red light), one can understand the reliance on sensory cues. 
It is apparent that many environmental cues determine the outcome of social interactions. With the assumption that all group members begin with equal fighting abilities, environmental effects or diminished sensory cues will most likely disrupt the typical intrinsic behavior. Furthermore, when multiple cues are diminished, the influence may be additive or behave synergistically in altering a behavior. Thus, by examining reliance on single sensory systems on well-defined social behavior, we can begin to understand environmental impacts on populations/species. We compared social interactions in white light to experiments in red light to understand the photoreceptors influence on social interactions.

Past studies have examined many extrinsic factors that influence intraspecific aggression, such as shelter acquisition $[19,62,63]$, chemical communication $[5,23,64]$, mating [65], food preferences [66], and starvation [67, 68]. An area not yet addressed is the extrinsic factor of "out of water" for crayfish social interactions, and it is unclear whether the hydrodynamics of natural habitats allow for the successful use of chemical signals and typical behavior during social interactions in nature. Thus, the purpose of this study is to present quantitative analysis of environmental influence on social interactions in two species of crayfish with special reference to reliance of different primary sensory modalities.

Intrinsic and extrinsic factors affect intraspecific aggression in many ways, and both should be examined for the impact on agonistic behavior. Herein, a simple additive model for this integration of multiple sensory systems as well as multiple environmental factors in an individual's expected fighting ability determined the impact of additive effects. Examination of environmental influence on behavior was through the measure of fighting strategy and intensity of interaction in two species (Procambarus clarkii, sighted surface crayfish and Orconectes australis packardi, blind cave crayfish).

Due to distinct behavioral, anatomical, biochemical, morphological, and/or physiological adaptations of cave organisms, there is a fascination and interest in understanding how they are able to adapt and survive in extreme environments. Cave crayfish show the general characteristics of anatomical and morphological adaptations of most cave organisms. Specifically when compared to surface crayfish, cave crayfish are smaller in size, have longer/thinner appendages, possess highly developed nonvisual sensory capabilities, and lack pigment and eyes [69]. In addition, behavioral, physiological, and biochemical adaptations have been identified in cave crayfish such as a decrease in locomotion and oxygen consumption, as well as a decrease in metabolic rates [70]. These are related to a reduction in energy from limited food sources and/or oxygen availability in cave systems [71-73]. Thus, these distinct evolutionary adaptations allows for studies discerning behavioral differences in two species of crayfish. Another goal of this study was to identify species-specific behaviors through comparison of cave and a surface species, as well as determining the environmental and olfactory influence on intrinsic behaviors.

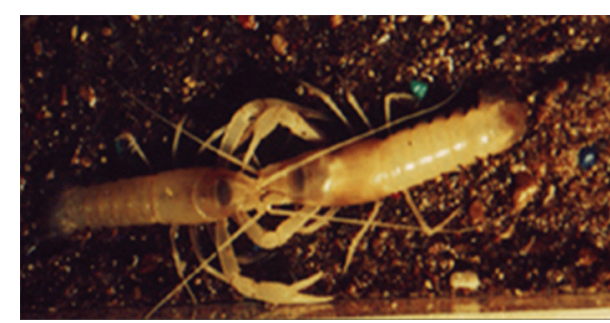

FIGURE 1: Blind cave crayfish, Orconectes packardi australis, engaged in an agonistic encounter.

\section{Methods}

2.1. Animals. Crayfish, Procambarus clarkii (sighted), measuring $5.0-6.25 \mathrm{~cm}$ in body length were obtained commercially (Atchafalaya Biological Supply Co., Raceland, LA, USA). Crayfish, Orconectes australis packardi (Rhoades) (the blind crayfish), measuring $4.6-6.4 \mathrm{~cm}$, were obtained from the Sloan's Valley Cave System near Somerset, KY, USA (state collecting permits were obtained for this study; Figure 1). A total of 25 sighted and 15 blind crayfish were used in the study. Crayfish pairs were randomly chosen from the naïve population stock. The order in which the trials occurred was random. No two crayfish were paired together more than once; thus, all encounters were with conspecifics not previously known to each other. Only male crayfish were used in this study. Animals were housed individually in rectangular plastic containers and cared for in the same manner, except for O. a. packardi that were covered with black plastic to omit light in an aquatic facility within our regulatedtemperature laboratory $\left(17-20^{\circ} \mathrm{C}\right)$. P. clarkii were on a 12 hour period light-dark cycle. All crayfish were fed dried fish pellets weekly before and throughout the experiments. Crayfish handling was conducted by using a glass beaker to transfer crayfish from one container to the another. Due to housed containers being cleaned weekly, crayfish were handled often; the limited handling during experimentation is assumed to have little to no effect on the internal status of the crayfish. Only crayfish in their intermolt stage, possessing all walking legs and both chelipeds were used in these studies.

2.2. Social Interactions. Initial experiments (i.e., low light) were focused on characterizing the general behavioral interactions for both species of crayfish. Crayfish were randomly distributed into fourteen different conditions as discussed below. Social interactions were staged in size-matched males. An interaction behavioral scoring index was developed (Table 1(a)) for species comparison of $P$. clarkii and $O$. australis packardi. Observational preexperimental trials identified typical crayfish behavior to establish a quantifiable scale for interactions based on both aggressiveness, as well as intensity (time duration of the interaction, Table 1(b)). Crayfish male pairs of approximate equal size were staged in a glass aquarium and videotaped for one hour, allowing for interaction without outside interference. The crayfish were monitored indirectly with a TV monitor. Trials conducted in low light in the water served as controls for the sighted 
TABLE 1: Social interaction scoring bioindex. (a) Indicates the behavioral scoring bioindex used to quantify behavior during each trial in the experimental conditions. (b) Indicates the intensity scale based upon time duration in which the pairs were engaged in a specific behavior.

(a)

\begin{tabular}{lc}
\hline 0 & No interaction \\
1. & Territory invasion \\
2. & Intentional touching \\
3. & Acknowledgment \\
4. & Threat display \\
5. & Chase \\
6. & Grasp/strike \\
7. & Dismemberment \\
\hline
\end{tabular}

(b)

\begin{tabular}{cc}
\hline 0.1 & $1-15$ seconds \\
0.2 & $16-30$ seconds \\
0.3 & $31-45$ seconds \\
0.4 & $>45$ seconds \\
\hline
\end{tabular}

crayfish, while trials conducted in red light in water act as controls for blind crayfish. The index was then used to quantify each of the trials across conditions and species comparison. Behavioral scores were assigned to pairs of crayfish (not individual scoring) for every interaction that occurred during the 60-minute time period.

2.3. Behavioral Analysis. Previous research and prior observation of aggressive interactions between individuals indicate that the behavior could be classified into several rather distinct categories. These categories represent behavior patterns in what are relatively stereotyped and which are known to be typical behaviors of sighted crayfish. Briefly the behavioral acts established are as follows (also see Table 1(a)).

0-No interaction: no encounter without any evidence of awareness of other individual.

1-Territory invasion/approach/retreat: deliberate movement towards other individual and a direct, initiation into conspecifics space and/or movement away.

2-Intentional touching: a short rapid movement forward directed at individual.

3-Acknowledgment/standoff: facing one another without visual threat display.

4-Meral spread/threat display: outward raising and spreading of the chelipeds.

5-Chase: pursuit after the individual.

6-Grasp/strike: a blow to or seizing of other individual.

7-Dismemberment: very aggressive action to individual in which dismemberment or likelihood of killing is apparent.
Most of the general characteristics are previously described in Dingle and Caldwell [74]. Interactions typically began with an invasion of territory or an acknowledgment/ standoff. Termination of the interaction occurred when the observer determines that individuals no longer appear to be directing behavior at each other. Communication may be occurring, but since the purpose of this study was to concentrate on aggressive interactions, no attempt was made to analyze other possible communicative behaviors. Quantification of behavior was based upon total number of interactions as well as the length of each individual interaction.

Each trial was critically analyzed to categorize crayfish behavior, as well as identify general behavioral trends within and across species. For each environmental condition (i.e., low light, red light, and no antennules), five trials $(N=$ $5)$ were run in the water and five trials $(N=5)$ were run out of the water. All trials were digitally recorded and analyzed through video analysis to record behavioral scores and intensity. To understand behavioral trends, 3D graphs combined all trials together for comparison of the type of behavior as well and intensity of each encounter. The duration of an interaction was used as a measure of interaction intensity. Since interactions are known to be relatively short, a time scale was used (Table 1(b)).

2.4. Environmental Conditions. The various environmental conditions that were used are listed in Table 2. Social interactions were examined in and out of water in low light (25lux). "In water" studies used a glass aquarium $(20 \mathrm{~cm} \times 10 \mathrm{~cm} \times$ $12 \mathrm{~cm}) 4 \mathrm{~cm}$ filled from the top with aerated water. "Out of water" studies were conducted using the same aquarium but without water and still providing wet sand for the animals to walk on. "In water" studies (control) for both sighted and blind crayfish were compared to other environmental conditions to determine changes in intrinsic behaviors. This part of the study examined: (1) sighted "in water," (2) sighted "out of water," (3) blind "in water," and (4) blind "out of water".

Social interactions were also observed in red light. Red light conditions used a filtered red light (2.5 Lux) to remove the visual sensory stimulation for the sighted crayfish and the stimulation of the caudal photoreceptors in the cave crayfish. The red light (Kodak Adjustable Safeway Lamp, 15 watts), was previously noted to be a wavelength not detected by crayfish $[9,40]$ thus providing no visual sensory stimulation. The purpose is to examine the reliance of visual cues for sighted crayfish out of water when chemosensory cues are diminished. Furthermore, using blind crayfish in red light allowed us to help determine if low light induces a stress response that influences social behavior. We examined these conditions in this part of the study: (1) sighted/in water/red light, (2) sighted/out of water/red light, (3) blind/in water/red light, and (4) blind/out of water/red light (Table 2).

The removal of olfactory cues was conducted by removing the antennules (primarily sensory system for chemical detection) with sharp scissors at the base of the antennules by the first annuli. There was no death associated with antennulectomy as this is not that invasive of a surgery for crayfish. In 
TABLE 2: Social interaction conditions for both species of crayfish. Social interactions were observed both in and out of the water for sighted and blind crayfish. Assessment of different sensory modalities impact on intrinsic behavior was examined through methodical removal of one or many sensory cues.

\begin{tabular}{lccc}
\hline & Sighted & \multicolumn{2}{c}{ Blind } \\
In water & Out of water & In water & Out of water \\
\hline Low light & Low light & Low light & Low light \\
$\begin{array}{l}\text { Red light } \\
\text { Low light/no } \\
\text { antennules }\end{array}$ & $\begin{array}{c}\text { Red light } \\
\text { Low light/no }\end{array}$ & Red light & Red light \\
$\begin{array}{l}\text { Red light/no } \\
\text { antennules }\end{array}$ & $\begin{array}{c}\text { Red light/no } \\
\text { antennules }\end{array}$ & $\begin{array}{c}\text { Red light/no } \\
\text { antennules }\end{array}$ & $\begin{array}{c}\text { Red light/no } \\
\text { antennules }\end{array}$ \\
\hline
\end{tabular}

fact, there is little blood loss as well since this is not that wide of a region as compared to the very base of the antennules next to the cephalothorax. The animals were held for 3 days for recovery after antennulectomy. "In water" and "out of water" studies were again conducted for both species of crayfish. The purpose of removing the antennules was to further understand the reliance of visual cues for sighted crayfish and to understand impacts on social behavior for blind crayfish if there was a lack of environmental olfactory cues. These set of conditions compared (1) sighted/in water/no antennules, (2) sighted/out of water/no antennules, (3) blind/in water/no antennules, and (4) blind/out of water/no antennules.

To determine the reliance on environmental cues during social interactions for sighted crayfish, both chemosensory and visual cues were removed. Social interactions were examined for sighted crayfish only in red light and with the removal of antennules in order to compare these two conditions: (1) sighted/in water/red light/no antennules and (2) sighted/out of water/red light/no antennules.

2.5. Recording ECGs. An autonomic response was examined when sighted crayfish $(N=5)$ were placed into the experimental aquarium for interactions. Crayfish pairs were randomly chosen from the naïve population stock for "in water" and "out of water" trials. Order of which trials occurred first was random. There were multiple days between starting the trials to ensure that social recognition was unlikely. Crayfish were wired to record electrocardiograms (ECGs) for heart rate (HR) [75-77]. In brief, two insulated stainless steel wires (diameter 0.005 inches and with the coating 0.008 inches; A-M Systems, Carlsborg, WA, USA) were placed under the dorsal carapace directly over the heart 3 days prior to experimentation. Wires were inserted through holes drilled in the carapace and cemented in place with instant adhesive (Eastman, 5-min drying epoxy). These two wires were placed to span the heart in a rostral-caudal arrangement to insure an accurate impedance measure during each heart contraction as shown in Figure 2. A lid was used to prevent the crayfish from exiting the chamber but left a small section uncovered for the wires to exit the chamber and did not prohibit the crayfish from moving freely. All physiological measures were recorded though an impedance detector which measured dynamic resistance between the

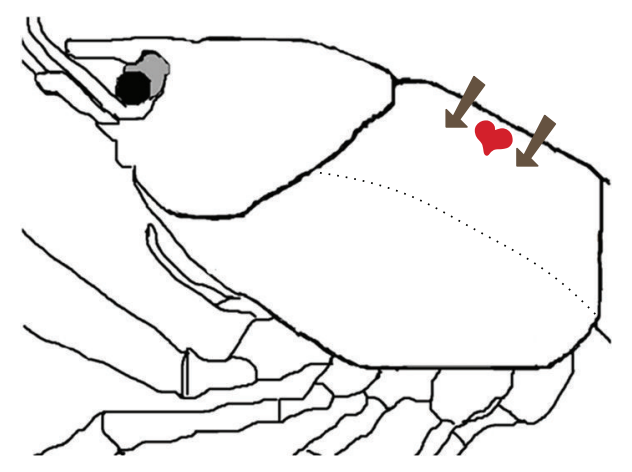

FIGURE 2: Schematic representation for the placement of the recording wires for monitoring the heart from a crayfish (Procambarus clarkii.). On the dorsal carapace, large arrows represent the two wires which spanned the rostral-caudal axis of the heart to monitor any change in the dynamic resistance, which is used as a measure of heart rate.

stainless steel wires and recorded on-line to a PowerLab via a PowerLab/4SP interface (AD Instruments). All events were measured and calibrated with the PowerLab Chart software version 5.5.6 (AD Instruments, Australia). Previous studies showed that 3 days was enough time for the animals to return to physiological measurements similar to levels prior to handling [78]. Cave crayfish typically have a thinner, more brittle exoskeleton resulting in more delicate handling during wiring.

Analysis of the response consisted of heart rate in beats per minute (BPM). HR was monitored in and out of water under control conditions to determine physiological responses during social interactions. This provided an internal measure to external cues. The experimental procedure consisted HR recordings before, during, and after social interactions. HR was analyzed to provide a BPM to note changes in the internal response based upon interactions, as well as environmental conditions.

2.6. Statistical Analysis. Parametric tests (ANOVA and $t$ test) were used when comparing differing levels of behavior and levels of intensity. When sufficient evidence for normality was violated, Mann Whitney Rank Sum was used to compare different experimental conditions on the same species. All graphs and statistical tests were performed in SigmaPlot Version 11.0 and R 2.15.0 (Systat Software Inc., San Jose, CA, USA). Additional variables were created such as maximum behavior over the 60-minute trial, time to first maximum behavior observed, the intensity of the first maximum, the number of encounters, number of encounters at maximum behavior, and total intensity of all maximum behavior encounters.

\section{Results}

3.1. Social Behavior in Low White Light. Five pairs of sighted and five pairs of blind crayfish were allowed to separately interact for 60 minutes in low white light (25lux) to determine typical behavioral interactions. For sighted crayfish 
TABLE 3: Total number of social interaction across study conditions for sighted crayfish. Social interactions were observed for both "in water" and "out of water." Each row corresponds to the total number of interactions for a given behavioral score. Each column corresponds to an environmental condition. In this and succeeding tables, the numbers in brackets are the total "out of water" interactions.

\begin{tabular}{|c|c|c|c|c|}
\hline Behavior & Low light & Red light & No antennules & Red light/no antennules \\
\hline Invasion (1) & $183(120)^{* * *}$ & $101(77)^{* * *}$ & $47(54)^{*}$ & $54(58)^{\mathrm{NS}}$ \\
\hline Touching (2) & $160(97)^{* * *}$ & $107(120)^{* *}$ & $98(135)^{* * *}$ & $70(99)^{* * *}$ \\
\hline Acknowledgment (3) & $117(44)^{* * *}$ & $41(33)^{*}$ & $43(20)^{* *}$ & $25(10)^{* *}$ \\
\hline Threat display (4) & $108(38)^{* * *}$ & $33(22)^{*}$ & $39(26)^{*}$ & $43(5)^{* * *}$ \\
\hline Chase (5) & $68(18)^{* * *}$ & $51(10)^{* * *}$ & $34(6)^{* * *}$ & $43(2)^{* * *}$ \\
\hline Grasp (6) & $49(2)^{* * *}$ & $63(5)^{* * *}$ & $31(2)^{* * *}$ & $13(2)^{* * *}$ \\
\hline Dismemberment (7) & $27(0)^{* * *}$ & $20(2)^{* * *}$ & $8(0)^{* * *}$ & $4(1)^{* * *}$ \\
\hline
\end{tabular}

TABLE 4: Total number of social interaction across study conditions for blind crayfish. Social interactions were observed both "in water" and "out of water." Each row corresponds to the total number of interactions for a given behavioral score. Each column corresponds to an environmental condition.

\begin{tabular}{lccc}
\hline Behavior & Low light & Red light & $\begin{array}{c}\text { Red light/no } \\
\text { antennules }\end{array}$ \\
\hline Invasion (1) & $113(34)^{* * *}$ & $127(59)^{* * *}$ & $135(75)^{* * *}$ \\
Touching (2) & $87(27)^{* * *}$ & $160(89)^{* *}$ & $104(97)^{*}$ \\
Acknowledgment (3) & $60(5)^{* * *}$ & $65(6)^{* * *}$ & $93(22)^{* * *}$ \\
Threat display (4) & $36(3)^{* * *}$ & $37(5)^{* * *}$ & $55(0)^{* * *}$ \\
Chase (5) & $31(3)^{* * *}$ & $73(0)^{* * *}$ & $38(1)^{* * *}$ \\
Grasp (6) & $22(2)^{* *}$ & $29(0)^{* * *}$ & $4(0)^{\mathrm{NS}}$ \\
Dismemberment (7) & $3(1)^{\mathrm{NS}}$ & $8(0)^{*}$ & $0(0)^{\mathrm{NS}}$ \\
\hline
\end{tabular}

in water, they were shown to interact regularly within the time period, as well as escalate in interactions to high levels of aggression indicated by the total interactions for the behavioral scores (i.e., 6 and 7; Figure 3(a)). Interactions of sighted crayfish out of the water were shown to occur less often, and the interactions were shown to be less aggressive due to the few high scores (Figure 3(b)). There are few interactions overall, for cave crayfish. The cave crayfish show the same trend in decreasing their interactions out of water (Figures 4(a) and 4(b)). Both species exhibited significant differences in maximum behavior with crayfish in water being higher than out of water in low light (cave: $P=0.031$ and sighted: $P<0.001$ ). A similar outcome was found for the total number of interactions with in water being dominant over out of water (cave: $P=0.018$ and sighted: $P=0.022$ ). On average, sighted crayfish had significantly more total interactions compared to blind crayfish in low light $(P<0.001)$ (Figure 5). For either species, there was not a significant difference as to when the maximum behavior occurred. There was also no significant difference found in the duration of the maximal event or the total duration of all maximal events.

3.2. Analysis of Varying Environmental Conditions. Analysis of in water and out of water treatment groups showed significant changes in fighting strategy due to environmental effects. Specifically, out of water results alone or in combination with other conditions reveal that both species do not tail flip and show less intrusion into the conspecifics territory when compared to social interactions in the water (Figure 5). Blind crayfish were less responsive to the presence of conspecifics (fewer interactions), while surface crayfish showed an increase in visual displays (possible bluffing mechanism) when interacting out of the water, but failed to escalate the interaction when compared to interaction conducted in the water. Thus, for both species, out of the water has the most significant impact on intrinsic behavior and social interactions (Tables 3 and 4).

ANOVA statistical analysis for each environmental condition shows a significant difference between in water and out of water conditions as indicated in the summary tables (Tables 3 and 4). ANOVA values are as follows: sighted in red light $\left(F_{13,69}=33.7, P<0.001\right)$, blind in red light $\left(F_{13,69}=17.0, P<0.001\right)$, sighted in white light with no antennules $\left(F_{13,69}=17.8, P<0.001\right)$, sighted in red light with no antennules $\left(F_{13,69}=7.588, P<0.001\right)$, and blind in red light with no antennules $\left(F_{13,69}=19.3, P<0.001\right)$. Therefore, interactions occurring out of water showed that both species of crayfish were less likely to interact and more likely to explore their environment.

3.3. White versus Red Light. A significant difference was found in the number of interactions in blind cave crayfish $(P=0.029)$. In general, there were more interactions in red light than white light for the blind cave crayfish. There was no significant difference observed for the surface crayfish in any type of light. Both species did not exhibit any significant difference in the maximum behavior between white and red lights. Also, there was no significant difference detected in duration of interactions (Figures 6 and 7).

In fact, for the red light condition only, there was a marginal difference in the maximum behavior $(P=0.056)$ for sighted crayfish "in water" having a median value of 7 versus 5 "out of water." As for the cave crayfish, there was also a significant difference in median maximum behavior (6 in and 3 out $)(P=0.008)$ and a significant difference in the median number of interactions in red light (in 104 and out 33) $(P=0.0008)$.

3.4. With versus Without Antennules. The cave crayfish had more maximum behavioral encounters without antennules than with antennules $(P=0.012)$. Surface crayfish had more 


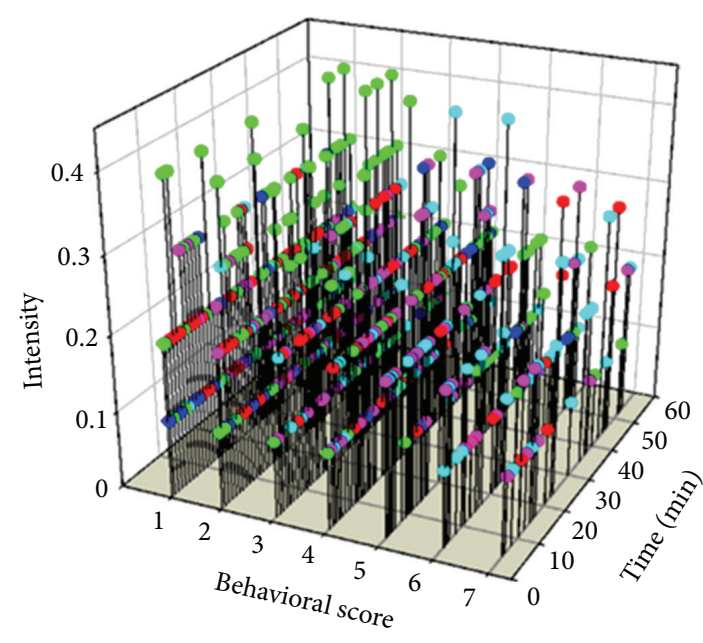

(a)

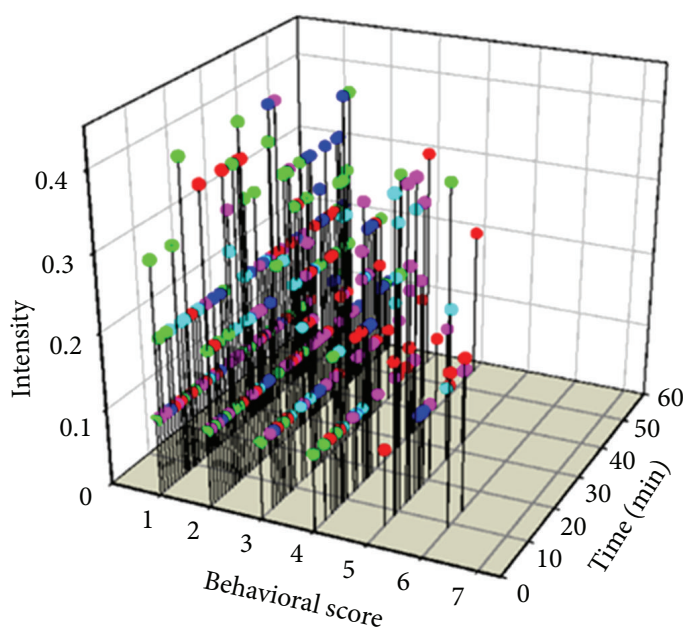

(b)

FIGURE 3: Comprehensive representation of social interactions for sighted crayfish in low white light (25 lux). (a) In water. (b) Out of water. A single vertical line indicates a given behavior at a specific point in time as well as the intensity of the behavior. The different colored points represent individual pairs in the trials $(N=5)$.

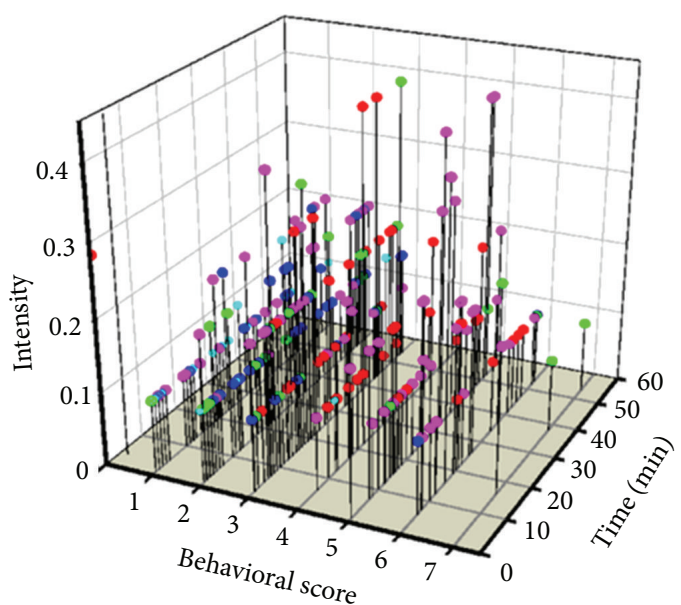

(a)

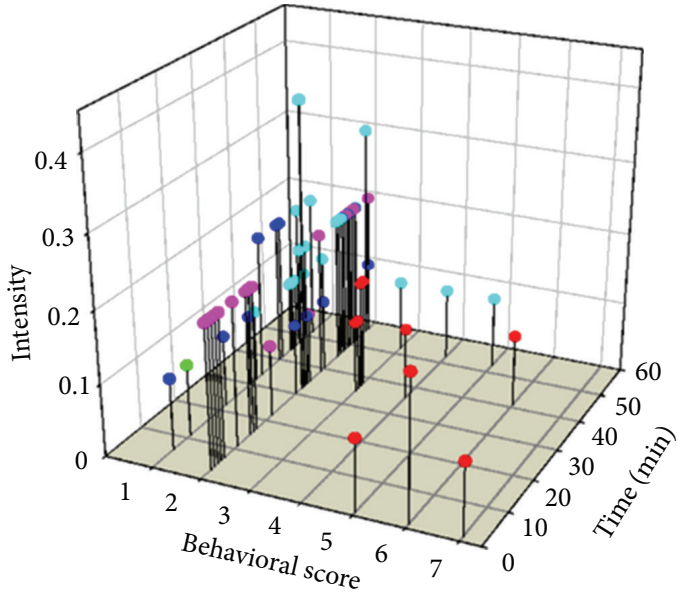

(b)

Figure 4: Comprehensive representation of social interactions for cave crayfish in low white light (25 lux). (a) In water. (b) Out of water. A single vertical line indicates a given behavior at a specific point in time as well as the intensity of the behavior. The different colored points represent individual pairs in the trials $(N=5)$.

general interactions with antennules rather than without antennules $(P<0.001)$. Again, there was no species identified significant difference in maximum behavior over the 60 minutes with or without antennules.

In red light, the cave crayfish did not show any significant difference over the 60 minutes in the variables measured. However, surface crayfish with antennules had more interactions over the time period than those without $(P=0.039)$. In low light, the sighted crayfish did show significant difference in the average time to the first maximum behavior (in 9 minutes versus out 19.8 minutes, $P=0.012$ ).

3.5. Recording ECGs. The physiological response of crayfish was recorded to characterize the autonomic response during social interactions as well as for environmental change.
Heart rate (HR) was recorded before, during, and after confrontation, plotted for each crayfish during the entire duration of the trial. A frequency plot of the raw traces shows dramatic changes in HR during interactions when comparing "in water" to "out of water" conditions (Figure 8). Specifically, there is a greater fluctuation for one individual (most likely the subordinate) during and after interactions. As consistent with previously described experiments, it is also shown that the "out of water" condition has fewer interactions. The raw traces show a rapid response during interactions, especially for one individual within a pair, as well as the continued response after the interaction is over. This suggests that "out of water" conditions have a greater effect on intrinsic factors, such as HR, for the individuals. This is most apparent for the individual most likely to become the subordinate since retreat 


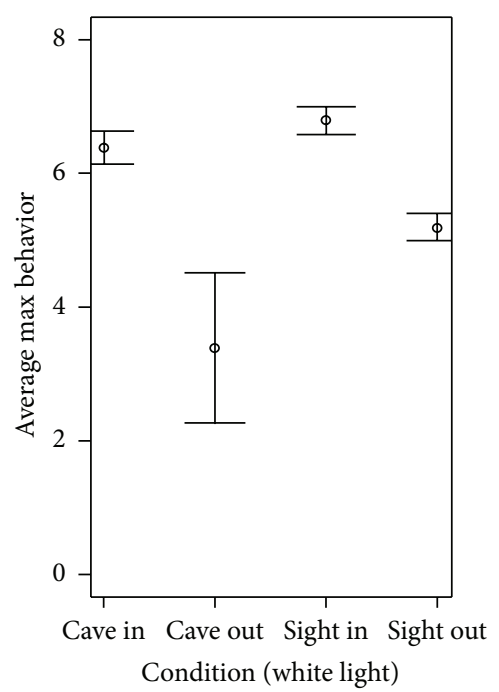

(a)

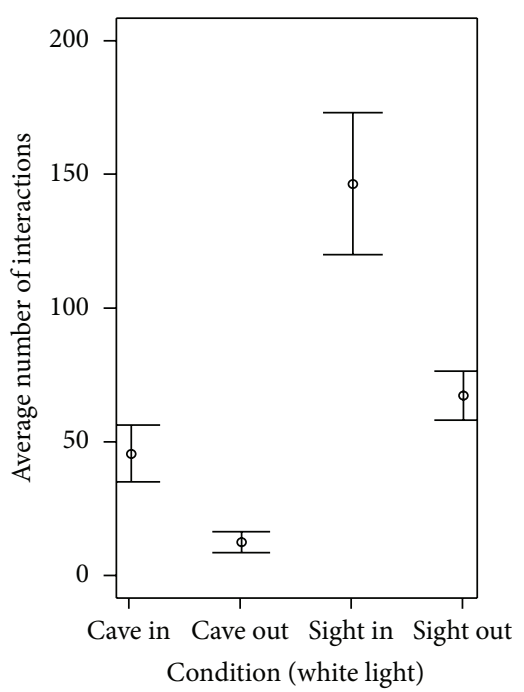

(b)

FIGURE 5: Comparison of cave and sighted crayfish in and out of water in low/white light. (a) The mean number of maximum behavior $( \pm$ SEM) is plotted for the four conditions. There is a significant difference between in and out of water for both species. (b) The mean number of total interactions $( \pm$ SEM) for the four conditions. There is also a significant decrease in both species between in and out of water in low light.

away from the conspecifics is not as feasible out of water and thus a greater chance of being attacked is likely to happen.

\section{Discussion}

This study demonstrated that environmental factors directly influence crayfish social interactive behavior. Here, we show that interactions were more aggressive and intense and more likely to end with a physical confrontation when they took place "in water" compared to "out of water" for two morphologically and genetically distinct species of crayfish. It is shown that altering environmental conditions induced crayfish to change their intrinsic behavior which resulted in modified social interactions and fighting strategy. For both species in low white light and in water, there was a high value of interactions, and those interactions were likely to escalate to higher levels of aggression (behavioural score of 5,6 , or 7 ). The duration of interaction was consistently longer in time (intensity of 0.3 or 0.4 ) when in water. Interestingly, when water was removed from the environment, the total number of interactions, as well as the aggression level and duration of each interaction, dramatically decreased for both species. Across all environmental conditions and exclusion of sensory systems (i.e., vision and chemosensory), removal of water produced the greatest and most consistent change in social interactions. For "out of water" trials, both species were shown not to tail flip (typical escape response), and they showed less intrusion into the conspecific's territory as well as being less likely to engage in social interactions. Importantly, while sighted crayfish did show an increase in visual displays out of the water, a possible bluffing mechanism [79], they failed to escalate in social interactions.

Interactions in red light for sighted crayfish did not appear to decrease aggression levels. This is most likely due to the chemical cues providing enough information about the environment and the conspecific. The removal of antennules along with red light showed a reduction in the number of interactions but did not diminish the aggression levels since many of the interactions escalated to a behavioral score of 5 (chase) and 6 (grasp/strike). When these crayfish were taken out of water in combination with the diminished sensory cues, there was a dramatic decrease in aggression of social interaction. This pattern was similar for blind crayfish in red light and the lack of antennules. There were very few interactions, and the aggression levels were dramatically decreased. Furthermore, heart rate measures during social interactions for a single pair of crayfish showed that "out of water" interactions have a large effect on the organism. It is likely that the dramatic effect on one of the individuals in the pair (most likely the subordinate) is due to an increased probability of injury which could occur in the absence of water. Although heart rate remained relatively unchanged when the crayfish were placed into the chamber, heart rate was shown to immediately decrease for one individual upon interaction with the conspecific.

Agonistic behavior is a fundamental factor of ecological nature, and aggression has been studied extensively in many invertebrate species such as bees [80, 81], ants [8284], termites [85], wasps [86], lobsters [87-90], crabs [91], and crayfish [92-94]. Ritualized displays and cues that are predicative of agonistic success enable the assessment a rivals' relative fighting ability [95]. Fights occurring in nature are known to be shorter, less intense, and more likely to end with a tail flip, but the animals do show the fundamental fight dynamics as seen in laboratory studies [96]. Fighting is potentially costly to each contestant for a variety of factors including time and energy [97-101] and physical injuring [101-106]. A limited number of studies integrate multiple 


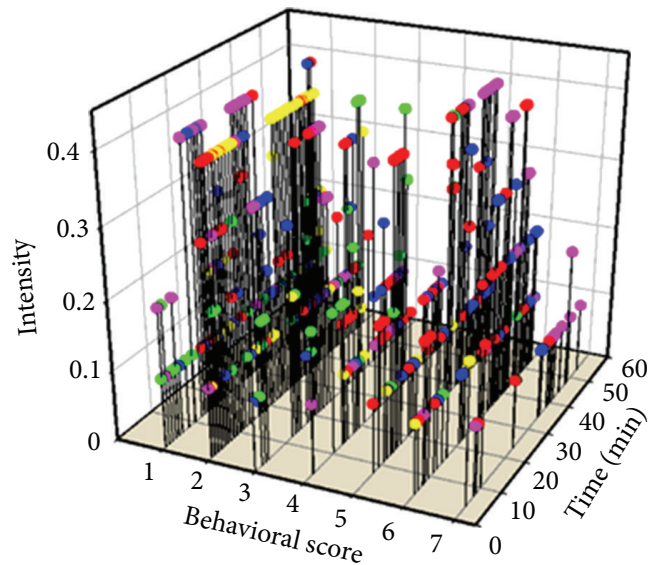

(a)

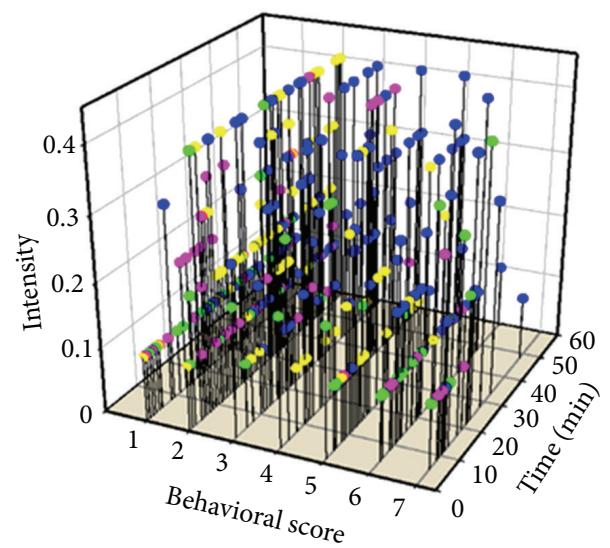

(c)

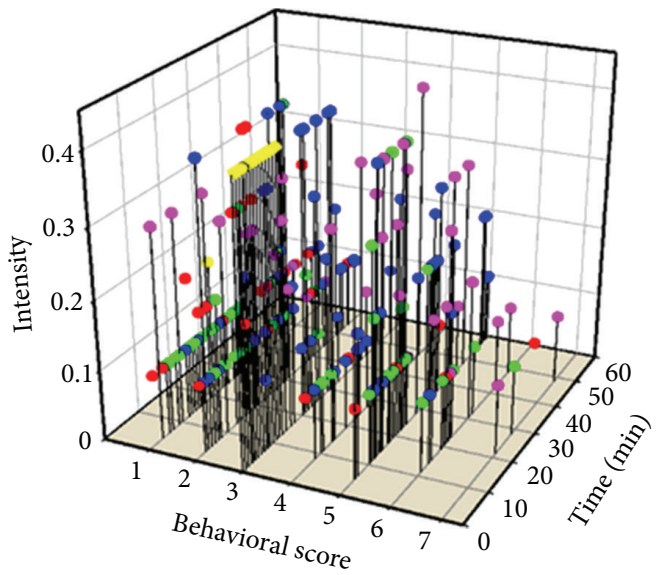

(e)

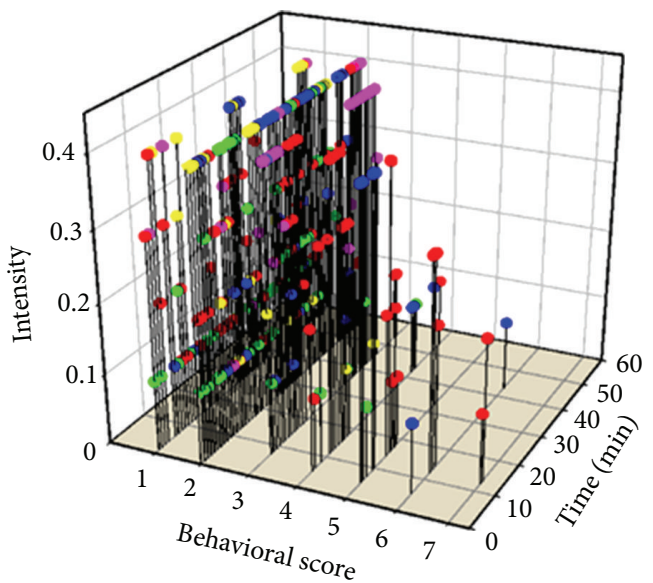

(b)

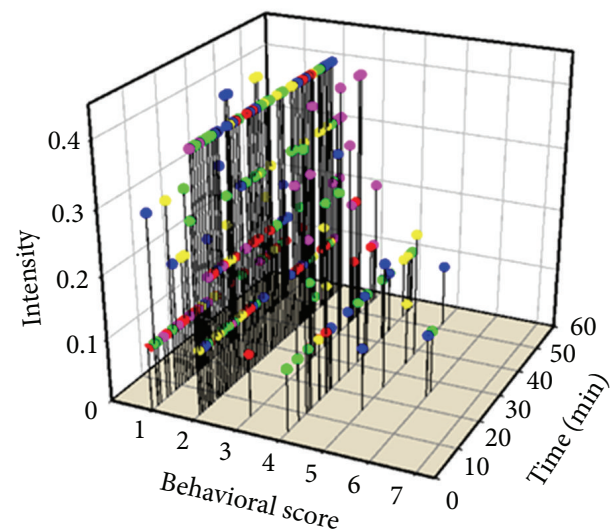

(d)

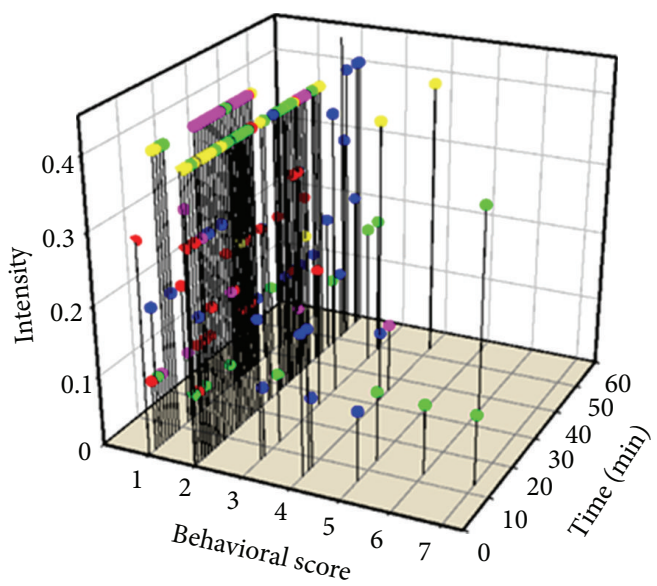

(f)

FIGURE 6: Comprehensive representation of social interactions for sighted crayfish in varying environmental conditions. (a) Red light and in water. (b) Red light and out of water. (c) Low white light, no antennules, and in water. (d) Low white light, no antennules and, out of water. (e) Red light, no antennules and, in water. (f) Red light, no antennules and, out of water. A single vertical line indicates a given behavior at a specific point in time as well as the intensity of the behavior. The different colored points represent individual pairs in the trials $(N=5)$. 


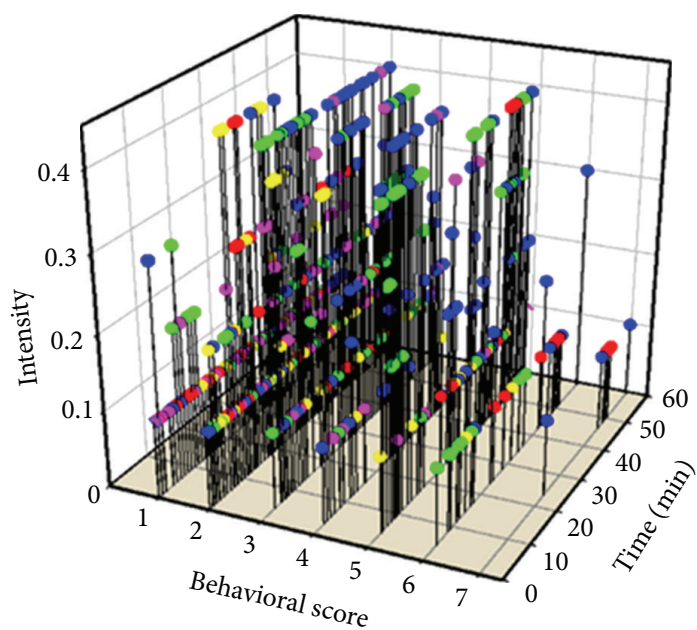

(a)

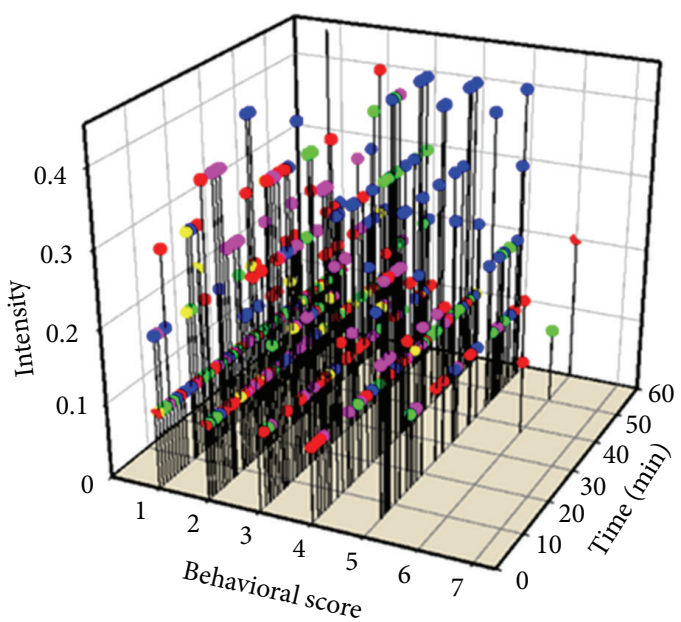

(c)

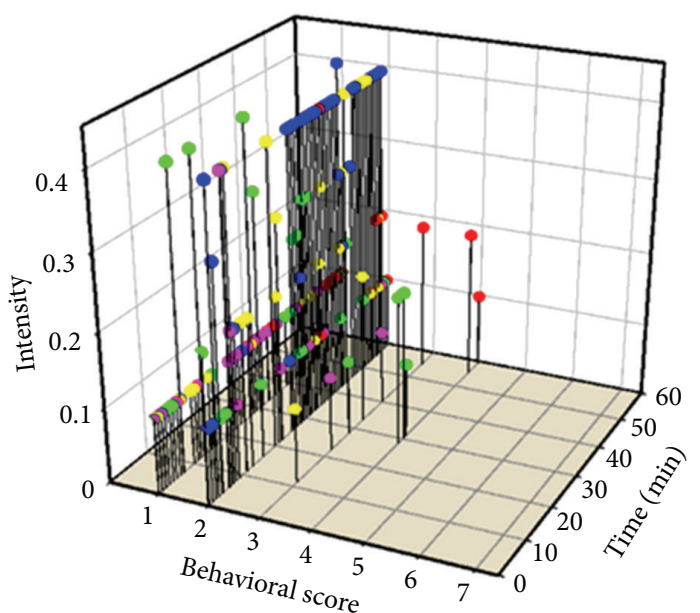

(b)

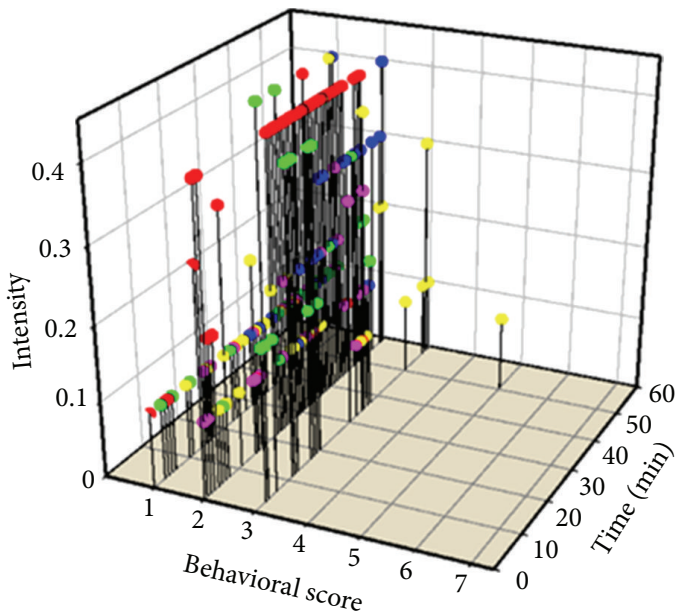

(d)

FIGURE 7: Comprehensive representation of social interactions for cave crayfish in varying environmental conditions (a) Red light and in water. (b) Red light and out of water. (c) Red light, no antennules and, in water. (d) Red light, no antennules and, out of water. A single vertical line indicates a given behavior at a specific point in time as well as the intensity of the behavior. The different colored points represent a total of each individual pairs of crayfish in the trials $(N=5)$.

factors that can influence contest behavior. Details of multiple factor sensory integration for any one species are virtually unknown.

The types of behavioral repertories we described are similar to those indexed by Huber and Kravitz [107] in the American lobster Homarus americanus and Bergman and Moore [96] in two species of crayfish Orconectes rusticus and Orconectes virilis. However, we used a scale of 0 to 7 , while Bergman and Moore used from (-2) to 5 scale. While the general descriptions were similar for each behavioral level, there were modified classifications in areas described in holding an opponent as a "do-see-do," which relates to a dance term, where we considered this behavior as a dismemberment grasp since they would try to twist the others cheliped off. We also indexed the time of interaction along with the aggression score and duration so that we could assess over time, the complexity of the repetitive interactions.
As expected, behavioral scores incrementally decreased with increasing the aggression levels and duration of interaction, as the hierarchy is likely established. Observational data from video as well as graph summaries document that the interactions do occur throughout the entire hour of the observation period. Specifically, interactions are just as likely to occur in the last ten minutes as they are in the first ten minutes. So even though a social status is being determined within the early interactions, there are continuous bouts to confirm or test the opponent within this initial hour of being introduced. Previous work on the crayfish Astacus astacus showed that the number of agonistic challenges, mean duration, and maximum intensity of encounters, were also initially high but then decreased steadily as the hierarchy developed [8]. Thus, the fact that interactions are still common after 50 minutes suggest that development of dominance relationships is incomplete. However, it should be noted 


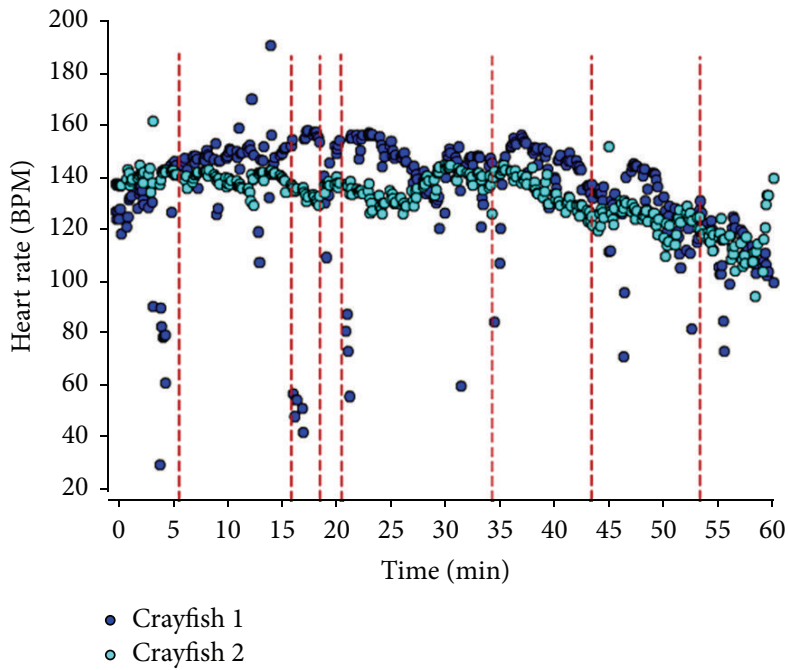

(a)

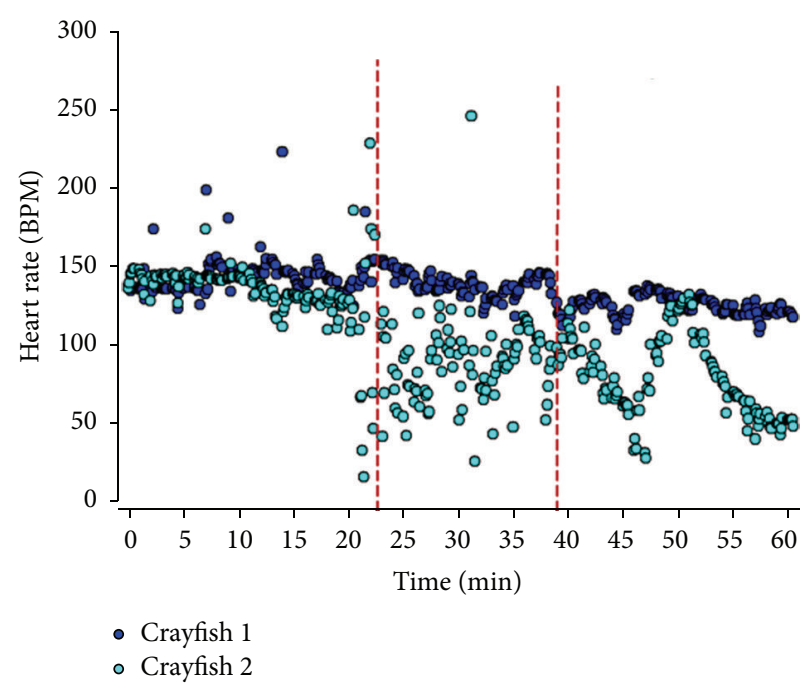

(b)

FIGURE 8: Physiological response of a single pair of crayfish. (a) "In water". (b) "Out of water". The dark blue line indicates crayfish one and light blue indicates crayfish two. Each point represents direct counts of each beat over 10-s intervals and then converted to beats per minute (BPM). The red dotted vertical lines indicate a physical interaction. The same pair was used in both conditions with multiple days in between each trial.

that a limitation to laboratory studies is the restriction of escape from an opponent. This would be less of an issue in natural ecosystems; however, small interaction arenas in the laboratory may lead to more aggressive interactions $[95,107]$.

If one were to document the sensory cues necessary for social dominance and maintenance of social hierarchy, a more in-depth study is required. In this study, the type of interactions and the effect of environment on these general levels of interactions were the focus. Many observations of crayfish behavior have been made to examine specific factors influencing intraspecific aggression such as in shelter acquisition $[19,62,63]$, chemical communication $[5,23,64]$, mating [65], food preferences [66], and starvation [67, 68]. These studies provide valuable information to determine intrinsic and extrinsic factors that affect agonistic interactions.

There are other extrinsic factors that influence intraspecific interactions such as previous history in agonistic encounters [96, 108, 109], different fighting strategies [110], and prior residence $[63,111]$. These can all significantly impact the outcome of social interactions. While we cannot control all these factors due to these organisms not being raised exclusively in the lab, we can use crayfish that have never been before placed together into a new environment that is not previously occupied by either in the past. Crayfish housed individually have been shown to be more aggressive [112] and that previous agonistic encounters with the same individuals can change the outcome of encounters [108, 113]. Since we did house the crayfish as individuals this might have raised their aggressiveness upon interacting.

While the use of a new environment will eliminate a prior residence variable, it does still pose other variables that need to be considered. The use of the new environment introduces the problem of the animals wanting to explore the new surroundings and thus could take away interest in the opponent. Searching/exploring behavior for both species of crayfish is likely a major drive. A previous study of cave crayfish showed this was especially true $[114,115]$. Therefore, animals might be in an anxious state in the conditions of pairing in this study (new environment), and upon meeting an opponent, they could be hesitant to interact as compared to an intruder invading one's space when an opponent is introduced to a resident's tank.

Studies examining short-term changes in behavior, specifically social interaction outcomes, have shown that physiological changes occur in both learning and the neuroendocrine system. The changes in either of these are associated with effects of experience on the neuroendocrine system of the individuals. Encounter behavior is modified as a result of learning [116-118]. Learning itself is a physiological change in synaptic transmission in specific neuronal pathways. Whether the changes are pre- or postsynaptic is not the issue, but only that physiological changes occur through experience [119]. Neuroendocrine changes such as in corticosteroids and androgens as a relation to fighting strategy has been well studied in vertebrates [120-126]. The relationship between dominance status and corticosteroid levels is less clear since in many cases the hormone levels can correlate positively, negatively, or not all with social rank as there appears to more of a species specific response [126129]. Serotonin (5-HT) has been associated with aggressive behavior [88, 130-133]. In invertebrates, increased serotonin shows an increase in aggression [134] since infusion of 5-HT in the hemocoel cavity of the crayfish Astacus astacus caused the animal to fight longer in an encounter $[6,135]$. It is most likely that after aggressive interactions, further physiological changes are associated with energy metabolism in modifying the neuroendocrine system due to energy depletion and hormonal actions which may even alter synaptic communication $[135,136]$. 
An intrinsic index is more reliable than a visual assessment of the animal's responsiveness and basal status. The autonomic control of the cardiovascular and respiratory systems can regulate the availability of oxygen and other nutrients needed for a behavioral response without causing any outward behavioral change [76]. Due to this fact, observational data alone incorrectly assess environmental factors effecting organisms. Previous work on crayfish showed that visual and/or chemical cues from other crayfish altered HR without any real apparent behavioral changes $[9,75]$. Thus, HR has been shown to be a good index in crayfish to use of environmental disturbances to fully understand if the animals can detect a change. Schapker et al. [76] showed that crayfish rapidly alter HR and ventilatory rate (VR) with changes in the environment and that HR and VR indicators were far more sensitive than behavioral data alone [137]. In addition, HR has been used to assess physiological state during copulation in crayfish which gave surprising results with a slowing of HR response in females but not males during copulation [138].

Our assessment of HR showed rapid and prolonged response to social interactions when out of water. This seems to be more prominent for one individual in the dyad since one will become the subordinate. This may also account for a stress response when one individual cannot retreat. Out of water conditions remove typical rapid escape responses; thus, individuals are more likely to sustain injuries during intense interactions. The disruption of social behavior "out of water" was consistently demonstrated with each environmental or physiological modification. There are many distinct experimental advantages to the use of crayfish in behavioral and physiological studies. In particular, the present experiments have shown that crayfish are suited to bring invertebrate studies of environmental effects on behavior and physiology to a level of more complex behavioral phenomena. This also provides a rich and vast foundation to study much broader evolutionary representations among taxa. The present study is built upon a wealth of existing research that has explored the social hierarchies in crayfish.

\section{Acknowledgments}

The authors are especially grateful to the undergraduates, Easter Bocook, Becca Liberty, Mary-Catherine Wright, Jessica Simpson, and Jessica McQuerry for their work on this project. Each of them worked very hard and conducted many of the behavioral interactions as well as watching videos to score behavior. Support was provided by a G. Ribble Fellowship for undergraduate studies in the Department of Biology at the University of Kentucky (EB, BL, and JM) and personal funds (RLC). There is no financial gain by the authors in relation to publishing this paper.

\section{References}

[1] W. C. Allee and R. H. Masure, "A comparison of maze behavior in paired and isolated shellparrakeets (Melopsittacus undulatus Shaw) in a two-alley problem box," Journal of Comparative Psychology, vol. 22, no. 1, pp. 131-155, 1936.
[2] T. E. Rowell, “The concept of social dominance," Behavioral Biology, vol. 11, no. 2, pp. 131-154, 1974.

[3] C. Drews, "The concept and definition of dominance in animal behavior," Behavior, vol. 125, pp. 283-313, 1993.

[4] R. V. Bovbjerg, "Dominance order in the crayfish Orconectes virilis (Hagen)," Physiological Zoology, vol. 26, pp. 173-178, 1953.

[5] R. V. Bovbjerg, "Some factors affecting aggressive behavior in crayfish," Physiological Zoology, vol. 29, pp. 127-136, 1956.

[6] R. Huber, K. Smith, A. Delago, K. Isaksson, and E. A. Kravitz, "Serotonin and aggressive motivation in crustaceans: altering the decision to retreat," Proceedings of the National Academy of Sciences of the United States of America, vol. 94, no. 11, pp. 59395942, 1997.

[7] F. A. Issa, D. J. Adamson, and D. H. Edwards, "Dominance hierarchy formation in juvenile crayfish Procambarus clarkii," Journal of Experimental Biology, vol. 202, no. 24, pp. 3497-3506, 1999.

[8] C. Goessmann, C. Hemelrijk, and R. Huber, "The formation and maintenance of crayfish hierarchies: behavioral and selfstructuring properties," Behavioral Ecology and Sociobiology, vol. 48, no. 6, pp. 418-428, 2000.

[9] H. Li, L. R. Listeman, D. Doshi, and R. L. Cooper, "Heart rate measures in blind cave crayfish during environmental disturbances and social interactions," Comparative Biochemistry and Physiology, vol. 127, no. 1, pp. 55-70, 2000.

[10] A. Lomnicki, Population Ecology of Individuals, Princeton University Press, Princeton, NJ, USA, 1988.

[11] N. Jiménez-Morales, A. R. Espinoza, K. Mendoza-Angeles, G. Roldán, and J. Hernandez-Falcon, "Memory and social interactions in crayfish," in Neuroscience Meeting Planner, Society for Neuroscience, New Orleans, La, USA, 2012.

[12] J. M. Smith, Evolution and the Theory of Games, Cambridge University Press, Cambridge, UK, 1982.

[13] C. J. Barnard and R. M. Sibly, "Producers and scroungers: a general model and its application to captive flocks of house sparrows," Animal Behaviour, vol. 29, no. 2, pp. 543-550, 1981.

[14] N. E. Collias, "Statistical analysis of factors which make for success in initial encounters between hens," American Naturalist, vol. 77, pp. 519-538, 1943.

[15] C. Barrette and D. Vandal, "Social rank, dominance, antler size, and access to food in snow-bound wild woodland caribou," Behaviour, vol. 97, no. 1-2, pp. 118-146, 1986.

[16] S. A. Frank, "Hierarchical selection theory and sex ratios I. General solutions for structured populations," Theoretical Population Biology, vol. 29, no. 3, pp. 312-342, 1986.

[17] J. Stahl, P. H. Tolsma, M. J. J. E. Loonen, and R. H. Drent, "Subordinates explore but dominants profit: resource competition in high arctic barnacle goose flocks," Animal Behaviour, vol. 61, no. 1, pp. 257-264, 2001.

[18] B. Sklepkovych, "The influence of kinship on foraging competition in Siberian jays," Behavioral Ecology and Sociobiology, vol. 40, no. 5, pp. 287-296, 1997.

[19] M. H. Figler, H. M. Cheverton, and G. S. Blank, "Shelter competition in juvenile red swamp crayfish (Procambarus clarkii): the influences of sex differences, relative size, and prior residence," Aquaculture, vol. 178, no. 1-2, pp. 63-75, 1999.

[20] S. Rohwer and P. W. Ewald, "The cost of dominance and advantage of subordination in a badge signaling system," Evolution, vol. 35, pp. 441-454, 1981.

[21] A. J. Hansen, "Fighting behavior in bald eagles: a test of game theory," Ecology, vol. 67, no. 3, pp. 787-797, 1986. 
[22] P. L. Rutherford, D. W. Dunham, and V. Alllison, "Antennule use and agonistic success in the crayfish Orconectes rusticus (Girard, 1852) (Decapoda, Cambaridae)," Crustaceana, vol. 69, pp. 117$122,1996$.

[23] R. A. Zulandt Schneider, R. W. S. Schneider, and P. A. Moore, "Recognition of dominance status by chemoreception in the red swamp crayfish, Procambarus clarkii," Journal of Chemical Ecology, vol. 25, no. 4, pp. 781-794, 1999.

[24] C. A. Bruski and D. W. Dunham, "The importance of vision in agonistic communication of the crayfish Orconectes rusticus. I. An analysis of bout dynamics," Behaviour, vol. 103, no. 1-3, pp. 83-107, 1987.

[25] M. R. Smith and D. W. Dunham, "Chela posture and vision: compensation for sensory deficit in the crayfish Orconectes propinquus (Girard) (Decapoda, Cambaridae)," Crustaceana, vol. 59, pp. 309-313, 1990.

[26] R. V. Bovbjerg, "Ecological isolation and competitive exclusion in two crayfish (Orconectes virilis and Orconectes immunis)," Ecology, vol. 51, pp. 225-236, 1970.

[27] E. A. Kravitz, S. Glusman, R. M. Harris-Warrick, M. S. Livingstone, T. Schwarz, and M. F. Goy, "Amines and a peptide as neurohormones in lobsters: actions on neuromuscular preparations and preliminary behavioural studies," Journal of Experimental Biology, vol. 89, pp. 159-175, 1980.

[28] J. Crane, "Combat, display and ritualization in fiddler crabs (Ocypodidae, Genus Uca)," Philosophical Transactions of the Royal Society B, vol. 251, no. 772, pp. 459-472, 1966.

[29] H. O. Wright, "Visual displays in brachyuran crabs: field and laboratory studies," Integrative and Comparative Biology, vol. 8, no. 3, pp. 655-665, 1968.

[30] G. W. Hyatt and M. Salmon, "Comparative statistical and information analysis of combat in the fiddler crabs, Uca pugilator and U. pugnax," Behavior, vol. 68, pp. 1-23, 1979.

[31] B. A. Hazlett and W. H. Bossert, "A statistical analysis of the aggressive communications systems of some hermit crabs," Animal Behaviour, vol. 13, no. 2-3, pp. 357-373, 1965.

[32] B. A. Hazlett, "Shell fighting and sexual behaviour in the hermit crab genera Paguristes and Calcinus with comments on Pagurus," Bulletin of Marine Science, vol. 22, pp. 806-823, 1972.

[33] P. J. Dunham, "Effect of chela white on agonistic success in a Diogenid hermit crab (Calcinus laevimanus)," Marine Behavior and Physiology, vol. 5, pp. 137-144, 1978.

[34] P. J. Dunham, "Sex pheromones in Crustacea," Biological Review, vol. 53, pp. 555-583, 1978.

[35] D. W. Dunham and A. J. Tierney, "The communicative cost of crypsis in a hermit crab Pagurus marshi," Animal Behaviour, vol. 31, no. 3, pp. 783-785, 1983.

[36] J. C. E. Scrivener, "Agonistic behavior of the American lobster, Homarus americanus (Mime-Edwards)," Fish Research Board Canada Techical Report 235, 1971.

[37] H. Dingle, "A statistical and information analysis of aggressive communication in the mantis shrimp Gonodactylus bredini Manning," Animal Behaviour, vol. 17, no. 3, pp. 561-575, 1969.

[38] A. R. Tilden, R. Brauch, R. Ball et al., "Modulatory effects of melatonin on behavior, hemolymph metabolites, and neurotransmitter release in crayfish," Brain Research, vol. 992, no. 2, pp. 252-262, 2003.

[39] R. L. Cooper, H. Li, L. Y. Long, J. L. Cole, and H. L. Hopper, "Anatomical comparisons of neural systems in sighted epigean and troglobitic crayfish species," Journal of Crustacean Biology, vol. 21, no. 2, pp. 360-374, 2001.
[40] H. Li and R. L. Cooper, "The effect of ambient light on blind cave crayfish: social interactions," Journal of Crustacean Biology, vol. 22, no. 2, pp. 449-458, 2002.

[41] T. Eisner and J. Meinwald, Chemical Ecology, National Academic Press, Washington, DC, USA, 1995.

[42] J. W. Bradbury and S. L. Vehrencamp, "Animal communication," in Encyclopcedia Britannica, 2009, http://www.britannica.com/ EBchecked/topic/25653/animal-communication.

[43] A. J. Tierney and D. W. Dunham, "Chemical communication in the reproductive isolation of the crayfishes Orconectes propinquus and Orconectes virilis (Decapoda, Cambaridae)," Journal of Crustacean Biology, vol. 2, pp. 544-548, 1982.

[44] R. A. Zulandt Schneider and P. A. Moore, "Urine as a source of conspecific disturbance signals in the crayfish Procambarus clarkii," Journal of Experimental Biology, vol. 203, no. 4, pp. 765771, 2000.

[45] T. Breithaupt and J. Petra, "Evidence for the use of urine signals in agonistic interactions of the American lobster," Biological Bulletin, vol. 185, pp. 318-323, 2003.

[46] B. A. Hazlett, “individual' recognition and agonistic behaviour in pagurus bernhardus," Nature, vol. 222, no. 5190, pp. 268-269, 1969.

[47] F. Gherardi and J. Atema, "Memory of social partners in hermit crab dominance," Ethology, vol. 111, no. 3, pp. 271-285, 2005.

[48] F. Gherardi and J. Tiedemann, "Binary individual recognition in hermit crabs," Behavioral Ecology and Sociobiology, vol. 55, no. 6, pp. 524-530, 2004.

[49] M. Vannini and F. Gherardi, "Dominance and individual recognition in Potamon fluviatile (Decapoda, Brachyura) possible role of visual cues," Marine Behavior and Physiology, vol. 8, pp. $13-20,1981$.

[50] R. L. Caldwell, "Cavity occupation and defensive behaviour in the stomatopod Gonodactylus festai: evidence for chemically mediated individual recognition," Animal Behaviour, vol. 27, no. 1, pp. 194-201, 1979.

[51] R. L. Caldwell, "A test of individual recognition in the stomatopod Gonodactylus festate," Animal Behaviour, vol. 33, no. 1, pp. 101-106, 1985.

[52] C. Karavanich and J. Atema, "Individual recognition and memory in lobster dominance," Animal Behaviour, vol. 56, no. 6, pp. 1553-1560, 1998.

[53] M. Lowe, "Dominance-subordinance relationships in the crawfish Cambarellus shufeldtii," Tulane Studies Zoology, vol. 4, pp. 139-170, 1956.

[54] J. L. Hurst, "Urine marking in populations of wild house mice Mus domesticus rutty. II. Communication between females," Animal Behaviour, vol. 40, no. 2, pp. 223-232, 1990.

[55] J. L. Hurst, "Urine marking in populations of wild house mice Mus domesticus rutty. I. Communication between males," Animal Behaviour, vol. 40, no. 2, pp. 209-222, 1990.

[56] J. L. Hurst, "Urine marking in populations of wild house mice Mus domesticus Rutty. III. Communication between the sexes," Animal Behaviour, vol. 40, no. 2, pp. 233-243, 1990.

[57] J. Atema and M. A. Steinbach, "Chemical communication and social behavior of the lobster, Homarus americanus, and other Decapod Crustacea," in Evolutionary Ecology of Social and Sexual Systems: Crustaceans as Model Organisms, J. E. Duffy and M. Thiel, Eds., pp. 115-144, Oxford University Press, New York, NY, USA, 2007.

[58] C. Ameyaw-Akumfi and B. A. Hazlett, "Sex recognition in the crayfish Procambarus clarkii," Science, vol. 190, no. 4220, pp. 1225-1226, 1975. 
[59] J. H. Thorp and K. S. Ammerman, "Chemical communication and agonism in the crayfish Procambarus acutus acutus," American Midland Naturlist, vol. 100, pp. 471-474, 1978.

[60] D. V. Devine and J. Atema, "Function of chemoreceptor organs in spatial orientation of the lobster, Homarus americanus: differences and overlap," Biological Bulletin, vol. 163, no. 1, pp. 144-153, 1982.

[61] C. Karavanich and J. Atema, "Olfactory recognition of urine signals in dominance fights between male lobster, Homarus americanus," Behaviour, vol. 135, no. 6, pp. 719-730, 1998.

[62] G. M. Capelli and P. A. Hamilton, "Effects of food and shelter on aggressive activity in the crayfish Orconectes rusticus (Girard)," Journal of Crustacean Biology, vol. 4, pp. 252-260, 1984.

[63] H. V. S. Peeke, J. Sippel, and M. H. Figler, "Prior residence effects in shelter defense in adult signal crayfish (Pacifastacus leniusculus (Dana)): results in same- and mixed-sex dyads," Crustaceana, vol. 68, no. 7, pp. 873-881, 1995.

[64] R. A. Zulandt Schneider, R. Huber, and P. A. Moore, "Individual and status recognition in the crayfish, Orconectes rusticus: the effects of urine release on fight dynamics," Behaviour, vol. 138, no. 2, pp. 137-153, 2001.

[65] A. M. Hill and D. M. Lodge, "Replacement of resident crayfishes by an exotic crayfish: the roles of competition and predation," Ecological Applications, vol. 9, no. 2, pp. 678-690, 1999.

[66] G. M. Capelli and B. L. Munjal, "Aggressive interactions and resource competition in relation to species displacement among crayfish of the genus orconectes," Journal of Crustacean Biology, vol. 2, no. 4, pp. 486-492, 1982.

[67] B. D. Hazlett, D. Rubenstein, and D. Rittschof, "Starvation, energy reserves, and aggression in the crayfish," Orconectes Virilis (Hagen), Crustaceana, vol. 28, pp. 11-16, 1975.

[68] A. M. Stocker and R. Huber, "Fighting strategies in crayfish Orconectes rusticus (Decapoda, Cambaridae) differ with hunger state and the presence of food cues," Ethology, vol. 107, no. 8, pp. 727-736, 2001.

[69] A. T. Gannon, V. G. Demarco, T. Morris, M. G. Wheatly, and Y. H. Kao, "Oxygen uptake, critical oxygen tension, and available oxygen for three species of cave crayfishes," Journal of Crustacean Biology, vol. 19, no. 2, pp. 235-243, 1999.

[70] E. A. Caine, "A comparative ecology of epigean and hypogean crayfish (Crustacea: Cambaridae) from northwestern Florida," American Midland Naturalist, vol. 99, pp. 315-329, 1978.

[71] P. W. Hochachka, Living without Oxygen: Closed and Open Systems in Hypoxia Tolerance, Harvard University Press, Cambridge, Mass, USA, 1980.

[72] K. Hüppop, "The role of metabolism in the evolution of cave animals," The National Speleological Society Bulletin, vol. 47, pp. 136-146, 1985.

[73] D. C. Culver, Cave Life. Evolution and Ecology, Harvard University Press, Cambridge, Mass, USA, 1982.

[74] H. Dingle and R. L. Caldwell, "The aggressive and territorial behaviour of the mantis shrimp Gonodactylus bredini manning (crustacea: stomatopoda)," Behaviour, vol. 33, no. 1, pp. 115-136, 1969.

[75] L. R. Listerman, J. Deskins, H. Bradacs, and R. L. Cooper, "Heart rate within male crayfish: social interactions and effects of 5HT," Comparative Biochemistry and Physiology, vol. 125, no. 2, pp. 251-263, 2000.

[76] H. Schapker, T. Breithaupt, Z. Shuranova, Y. Burmistrov, and R. L. Cooper, "Heart and ventilatory measures in crayfish during environmental disturbances and social interactions,"
Comparative Biochemistry and Physiology, vol. 131, no. 2, pp. 397-407, 2002.

[77] S. M. Bierbower and R. L. Cooper, "Measures of heart and ventilatory rates in freely moving crayfish," Journal of Visualized Experiments, vol. 32, article e1594, 2009.

[78] J. L. Wilkens, A. J. Mercier, and J. Evans, "Cardiac and ventilatory responses to stress and to neurohormonal modulators by the shore crab, Carcinus maenas," Comparative Biochemistry and Physiology C, vol. 82, no. 2, pp. 337-343, 1985.

[79] C. Ameyaw-Akumfi, "Appeasement displays in cambarid crayfish (Decapoda, Astacoidea)," Crustaceana, vol. 5, pp. 135-141, 1979.

[80] R. J. Paxton, P. F. Kukuk, and J. Tengö, "Effects of familiarity and nestmate number on social interactions in two communal bees, Andrena scotica and Panurgus calcaratus (Hymenoptera, Andrenidae)," Insectes Sociaux, vol. 46, no. 2, pp. 109-118, 1999.

[81] L. A. Halling, B. P. Oldroyd, W. Wattanachaiyingcharoen, A. B. Barron, P. Nanork, and S. Wongsiri, "Worker policing in the bee Apis florea," Behavioral Ecology and Sociobiology, vol. 49, no. 6, pp. 509-513, 2001.

[82] M. Beye, P. Neumann, M. Chapuisat, P. Pamilo, and R. F. A. Moritz, "Nestmate recognition and the genetic relatedness of nests in the ant Formica pratensis," Behavioral Ecology and Sociobiology, vol. 43, no. 1, pp. 67-72, 1998.

[83] E. Nowbahari, R. Feneron, and M. C. Malherbe, "Effect of body size on aggression in the ant, Cataglyphis niger (hymenoptera, formicidae)," Aggressive Behavior, vol. 25, pp. 369-379, 1999.

[84] W. D. Brown, C. Liautard, and L. Keller, "Sex-ratio dependent execution of queens in polygynous colonies of the ant Formica exsecta," Oecologia, vol. 134, no. 1, pp. 12-17, 2003.

[85] J. M. Polizzi and B. T. Forschler, "Factors that affect aggression among the worker caste of Reticulitermes spp. Subterranean termites (Isoptera: Rhinotermitidae)," Journal of Insect Behavior, vol. 12, no. 2, pp. 133-146, 1999.

[86] J. Ruther, S. Sieben, and B. Schricker, "Nestmate recognition in social wasps: manipulation of hydrocarbon profiles induces aggression in the European hornet," Naturwissenschaften, vol. 89, no. 3, pp. 111-114, 2002.

[87] B. L. Antonsen and D. H. Paul, "Serotonin and octopamine elicit stereotypical agonistic behaviors in the squat lobster Munida quadrispina (Anomura, Galatheidae)," Journal of Comparative Physiology A, vol. 181, no. 5, pp. 501-510, 1997.

[88] M. S. Livingstone, R. M. Harris-Warrick, and E. A. Kravitz, "Serotonin and octopamine produce opposite postures in lobsters," Science, vol. 208, no. 4439, pp. 76-79, 1980.

[89] H. V. S. Peeke, G. S. Blank, M. H. Figler, and E. S. Chang, "Effects of exogenous serotonin on a motor behavior and shelter competition in juvenile lobsters (Homarus americanus)," Journal of Comparative Physiology A, vol. 186, no. 6, pp. 575-582, 2000.

[90] S. B. Doernberg, S. I. Cromarty, R. Heinrich, B. S. Beltz, and E. A. Kravitz, "Agonistic behavior in naïve juvenile lobsters depleted of serotonin by 5,7-dihydroxytryptamine," Journal of Comparative Physiology A, vol. 187, no. 2, pp. 91-103, 2001.

[91] L. U. Sneddon, A. C. Taylor, F. A. Huntingford, and D. G. Watson, "Agonistic behaviour and biogenic amines in shore crabs Carcinus maenas," Journal of Experimental Biology, vol. 203, no. 3, pp. 537-545, 2000.

[92] R. Huber, A. G. Daws, S. B. Tuttle, and J. B. Panksepp, "Quantitative techniques for the study of crustacean aggression," in The Crustacean Nervous System, K. Wiese, Ed., pp. 186-203, Springer, Berlin, Germany, 2001. 
[93] L. Schroeder and R. Huber, "Fight strategies differ with size and allometric growth of claws in crayfish, Orconectes rusticus," Behaviour, vol. 138, no. 11-12, pp. 1437-1449, 2001.

[94] J. B. Panksepp and R. Huber, "Chronic alterations in serotonin function: dynamic neurochemical properties in agonistic behavior of the crayfish, Orconectes rusticus," Journal of Neurobiology, vol. 50, no. 4, pp. 276-290, 2002.

[95] E. A. Kravitz and R. Huber, "Aggression in invertebrates," Current Opinion in Neurobiology, vol. 13, no. 6, pp. 736-743, 2003.

[96] D. A. Bergman and P. A. Moore, "Field observations of intraspecific agonistic behavior of two crayfish species, Orconectes rusticus and Orconectes virilis, in different habitats," Biological Bulletin, vol. 205, no. 1, pp. 26-35, 2003.

[97] J. Haller and C. Wittenberger, "Biochemical energetics of hierarchy formation in Betta splendens," Physiology and Behavior, vol. 43, no. 4, pp. 447-450, 1988.

[98] J. Haller, "Muscle metabolic changes during the first six hours of cohabitation in pairs of male Betta splendens," Physiology and Behavior, vol. 49, no. 6, pp. 1301-1303, 1991.

[99] K. E. Thorpe, A. C. Taylor, and F. A. Huntingford, "How costly is fighting? Physiological effects of sustained exercise and fighting in swimming crabs, Necora puber (L.) (Brachyura, Portunidae)," Animal Behaviour, vol. 50, no. 6, pp. 1657-1666, 1995.

[100] J. R. P. Halperin, T. Giri, J. Elliott, and D. W. Dunham, "Consequences of hyper-aggressiveness in Siamese fighting fish: cheaters seldom prospered," Animal Behaviour, vol. 55, no. 1, pp. 87-96, 1998.

[101] F. C. Neat, A. C. Taylor, and F. A. Huntinford, "Proximate costs of fighting in male cichlid fish: the role of injuries and energy metabolism," Animal Behavior, vol. 55, pp. 875-882, 1998.

[102] S. N. Austad, "A game theoretical interpretation of male combat in the bowl and doily spider (Frontinella pyramitela)," Animal Behaviour, vol. 31, no. 1, pp. 59-73, 1983.

[103] B. Gottfried, K. Andrews, and M. Haug, "Breeding robins and nest predators: effect of predator type and defense strategy on initial vocalization patterns," Wilson Bulletin, vol. 97, pp. 183190, 1985.

[104] J. G. M. Robertson, "Male territoriality, fighting and assessment of fighting ability in the Australian frog Uperoleia rugosa," Animal Behaviour, vol. 34, no. 3, pp. 763-772, 1986.

[105] M. A. McPeek and P. H. Crowley, "The effects of density and relative size on the aggressive behaviour, movement and feeding of damselfly larvae (Odonata: Coenagrionidae)," Animal Behaviour, vol. 35, no. 4, pp. 1051-1061, 1987.

[106] P. H. Crowley, S. Gillett, and J. H. Lawton, "Contests between larval damselflies: empirical steps toward a better ESS model," Animal Behaviour, vol. 36, no. 5, pp. 1496-1510, 1988.

[107] R. Huber and E. A. Kravitz, "A quantitative analysis of agonistic behavior in juvenile American lobsters (Homarus americanus L.)," Brain, Behavior and Evolution, vol. 46, no. 2, pp. 72-83, 1995.

[108] D. I. Rubenstein and B. A. Hazlett, "Examination of the agonistic behaviour of the crayfish Orconectes virilis by character analysis," Behavior, vol. 50, no. 3-4, pp. 193-216, 1974.

[109] A. G. Daws, J. Grills, K. Konzen, and P. A. Moore, "Previous experiences alter the outcome of aggressive interactions between males in the crayfish, Procambarus clarkii," Marine and Freshwater Behaviour and Physiology, vol. 35, no. 3, pp. 139-148, 2002.
[110] R. C. Guiaşu and D. W. Dunham, "Initiation and outcome of agonistic contests in male form I Cambarus robustus girard, 1852 crayfish (Decapoda, Cambaridae)," Crustaceana, vol. 70, no. 4, pp. 480-496, 1997.

[111] H. V. S. Peeke, M. H. Figler, and E. S. Chang, "Sex differences and prior residence effects in shelter competition in juvenile lobsters, Homarus americanus Milne-Edwards," Journal of Experimental Marine Biology and Ecology, vol. 229, no. 1, pp. 149-156, 1998.

[112] P. J. Dunham, "Some effects of group housing upon the aggressive behavior of the lobster Homarus americanus," Journal of Fisheries Research Board Canada, vol. 29, pp. 598-601, 1972.

[113] T. Burk, An analysis of the social behaviour of crickets [Ph.D. thesis], Oxford University, 1979.

[114] S. Kellie, J. Greer, and R. L. Cooper, "Alterations in habituation of the tail flip response in epigean and troglobitic crayfish," Journal of Experimental Zoology, vol. 290, no. 2, pp. 163-176, 2001.

[115] Z. Shuranova, Y. Burmistrov, and C. I. Abramson, "Habituation to a novel environment in the crayfish Procambarus cubensis," Journal of Crustacean Biology, vol. 25, no. 3, pp. 488-494, 2005.

[116] R. F. Oliveira, P. K. McGregor, and C. Latruffe, "Know thine enemy: fighting fish gather information from observing conspecific interactions," Proceedings of the Royal Society B, vol. 265, no. 1401, pp. 1045-1049, 1998.

[117] L. A. Dugatkin, "Bystander effects and the structure of dominance hierarchies," Behavior Ecology, vol. 12, pp. 348-352, 2001.

[118] S. M. Bierbower, Z. P. Shuranova, K. Viele, and R. L. Cooper, "Comparative study of environmental factors influencing motor task learning and memory retention in sighted and blind crayfish," Brain and Behavior, vol. 3, no. 1, pp. 4-13, 2013.

[119] Y. Hsu, R. L. Earley, and L. L. Wolf, "Modulation of aggressive behaviour by fighting experience: mechanisms and contest outcomes," Biological Reviews of the Cambridge Philosophical Society, vol. 81, no. 1, pp. 33-74, 2006.

[120] R. P. Hannes, D. Franck, and F. Liemann, "Effects of rank order fights on whole-body and blood concentrations of androgens and corticosteroids in the male swordtail (Xiphophorus helleri)," Zeitschrift fur Tierpsychologie, vol. 65, pp. 53-65, 1984.

[121] K. L. Huhman, T. O. Moore, C. F. Ferris, E. H. Mougey, and J. L. Meyerhoff, "Acute and repeated exposure to social conflict in male golden hamsters: increases in plasma POMC-peptides and cortisol and decreases in plasma testosterone," Hormones and Behavior, vol. 25, no. 2, pp. 206-216, 1991.

[122] K. L. Huhman, T. O. Moore, E. H. Mougey, and J. L. Meyerhoff, "Hormonal responses to fighting in hamsters: separation of physical and psychological causes," Physiology and Behavior, vol. 51, no. 5, pp. 1083-1086, 1992.

[123] G. W. Schuett, H. J. Harlow, J. D. Rose, E. A. Van Kirk, and W. J. Murdoch, "Levels of plasma corticosterone and testosterone in male copperheads (Agkistrodon contortrix) following staged fights," Hormones and Behavior, vol. 30, no. 1, pp. 60-68, 1996.

[124] Y. Sakakura, M. Tagawa, and K. Tsukamoto, "Whole-body cortisol concentrations and ontogeny of aggressive behavior in yellowtail (Seriola quinqueradiata Temminck and Schlegel; Carangidae)," General and Comparative Endocrinology, vol. 109, no. 2, pp. 286-292, 1998.

[125] G. W. Schuett and M. S. Grober, "Post-fight levels of plasma lactate and corticosterone in male copperheads, Agkistrodon contortrix (Serpentes, Viperidae): differences between winners and losers," Physiology and Behavior, vol. 71, no. 3-4, pp. 335341, 2000. 
[126] O. Øverli, W. J. Korzan, E. Höglund et al., "Stress coping style predicts aggression and social dominance in rainbow trout," Hormones and Behavior, vol. 45, no. 4, pp. 235-241, 2004.

[127] K. A. Sloman, K. M. Gilmour, A. C. Taylor, and N. B. Metcalfe, "Physiological effects of dominance hierarchies within groups of brown trout, Salmo trutta, held under simulated natural conditions," Fish Physiology and Biochemistry, vol. 22, no. 1, pp. 11-20, 2000.

[128] M. N. Muller and R. W. Wrangham, "Dominance, cortisol and stress in wild chimpanzees (Pan troglodytes schweinfurthii)," Behavioral Ecology and Sociobiology, vol. 55, no. 4, pp. 332-340, 2004.

[129] J. Sands and S. Creel, "Social dominance, aggression and faecal glucocorticoid levels in a wild population of wolves, Canis lupus," Animal Behaviour, vol. 67, no. 3, pp. 387-396, 2004.

[130] F. Saudou, D. A. Amara, A. Dierich et al., "Enhanced aggressive behavior in mice lacking 5-HT(1B) receptor," Science, vol. 265, no. 5180, pp. 1875-1878, 1994.

[131] O. Cases, I. Self, J. Grimsby et al., "Aggressive behavior and altered amounts of brain serotonin and norepinephrine in mice lacking MAOA," Science, vol. 268, no. 5218, pp. 1763-1766, 1995.

[132] D. H. Edwards and E. A. Kravitz, "Serotonin, social status and aggression," Current Opinion in Neurobiology, vol. 7, no. 6, pp. 812-819, 1997.

[133] W. A. Weiger, "Serotonergic modulation of behaviour: a phylogenetic review," Biological Reviews, vol. 72, pp. 61-95, 1997.

[134] R. Huber and A. Delago, "Serotonin alters decisions to withdraw in fighting crayfish, Astacus astacus: the motivational concept revisited," Journal of Comparative Physiology A, vol. 182, no. 5, pp. 573-583, 1998.

[135] W. H. Wu and R. L. Cooper, "The regulation and packaging of synaptic vesicles as related to recruitment within glutamatergic synapses," Neuroscience, vol. 225, pp. 185-198, 2012.

[136] W. H. Wu and R. L. Cooper, "Role of serotonin in the regulation of synaptic transmission in invertebrate NMJs," Experimental Neurobiology, vol. 21, no. 3, pp. 101-112, 2012.

[137] Y.-S. Chung, R. M. Cooper, J. Graff, and R. L. Cooper, "The acute and chronic effect of low temperature on survival, heart rate and neural function in crayfish (Procambarus clarkii) and prawn (Macrobrachium rosenbergii) species," Open Journal of Molecular and Integrative Physiology, vol. 2, pp. 75-86, 2012.

[138] R. M. Cooper, H. Schapker-Finucane, H. Adami, and R. L. Cooper, "Heart and ventilatory measures in crayfish during copulation," Open Journal of Molecular and Integrative Physiology, vol. 1, no. 3, pp. 36-42, 2011. 

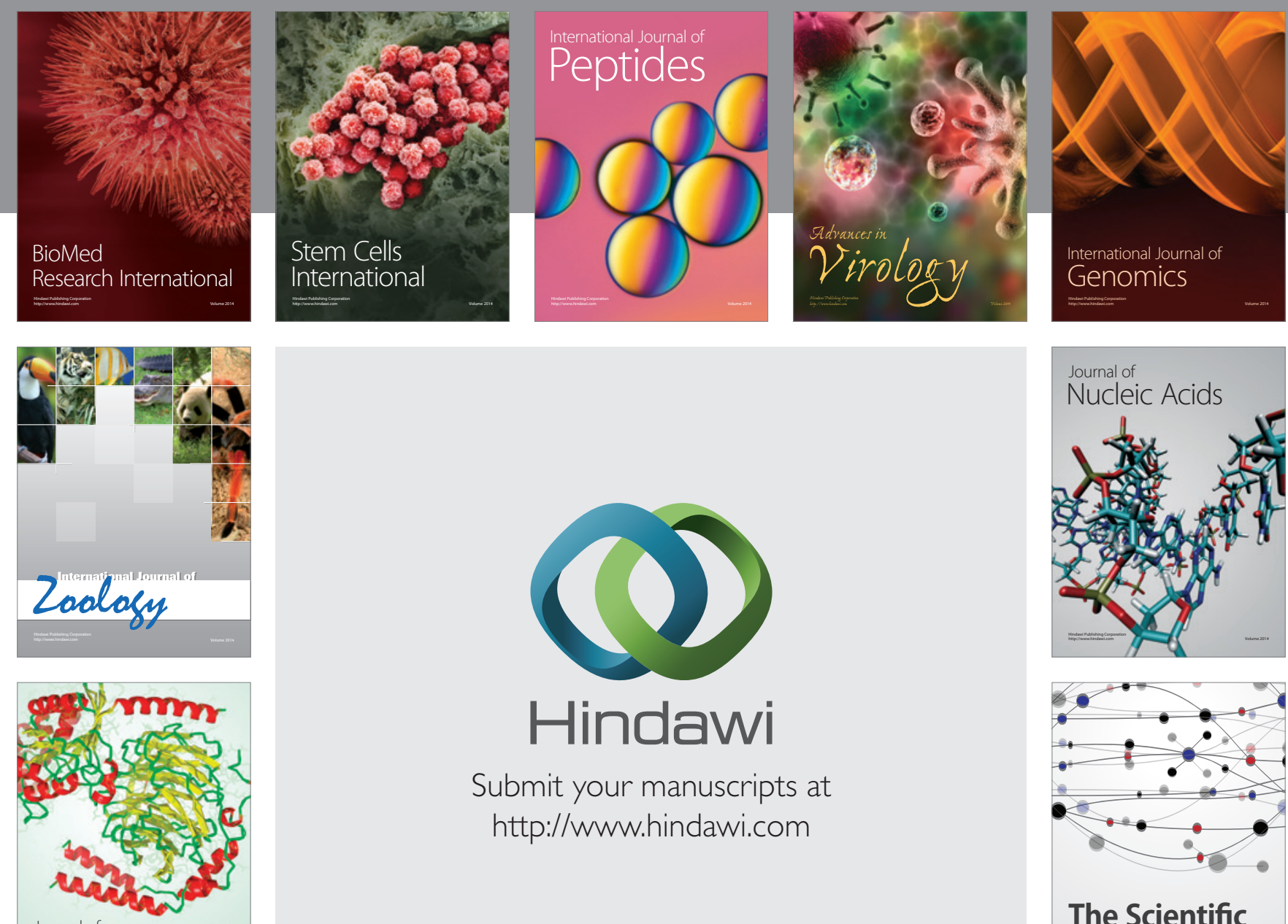

Submit your manuscripts at

http://www.hindawi.com

Journal of
Signal Transduction
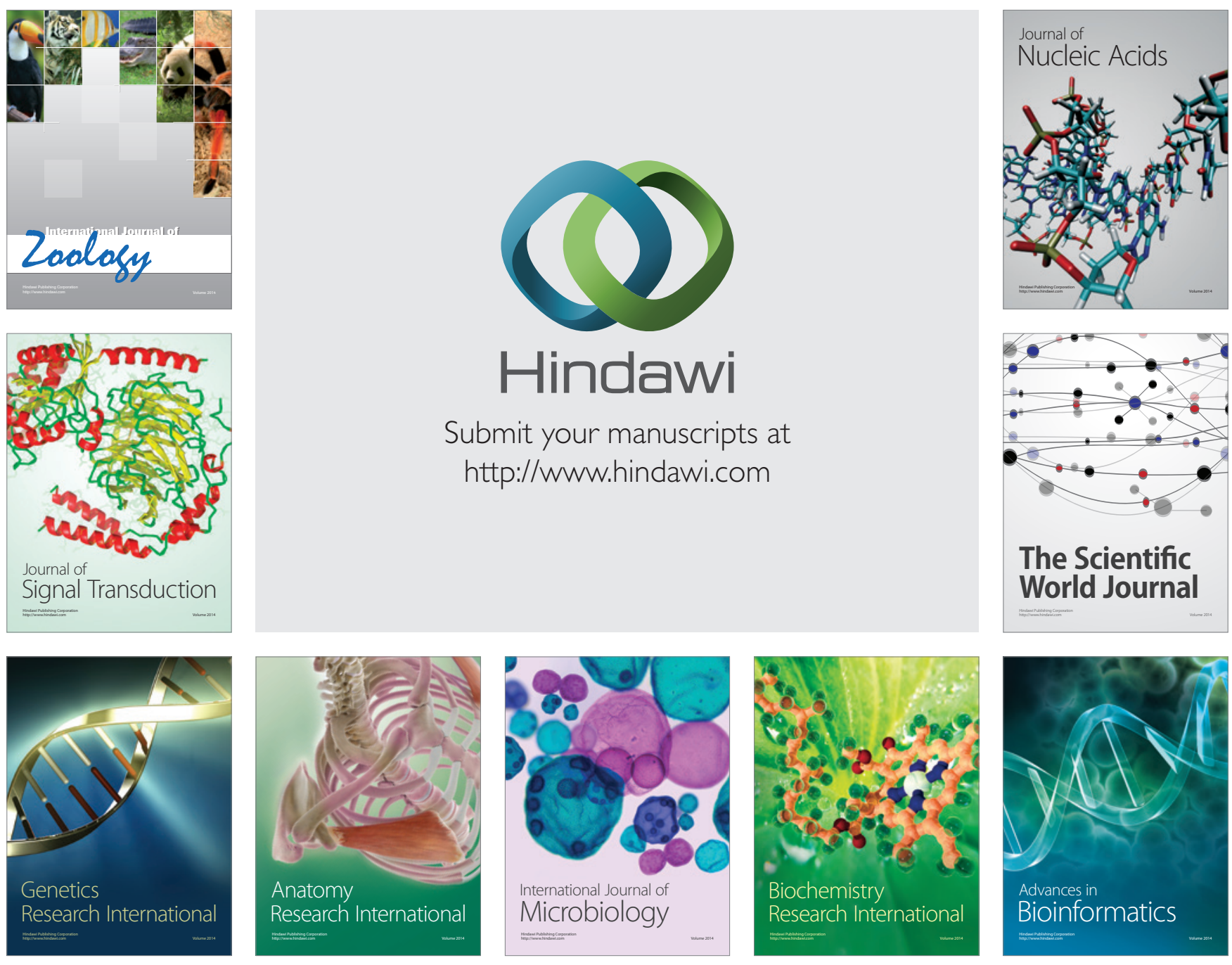

The Scientific World Journal
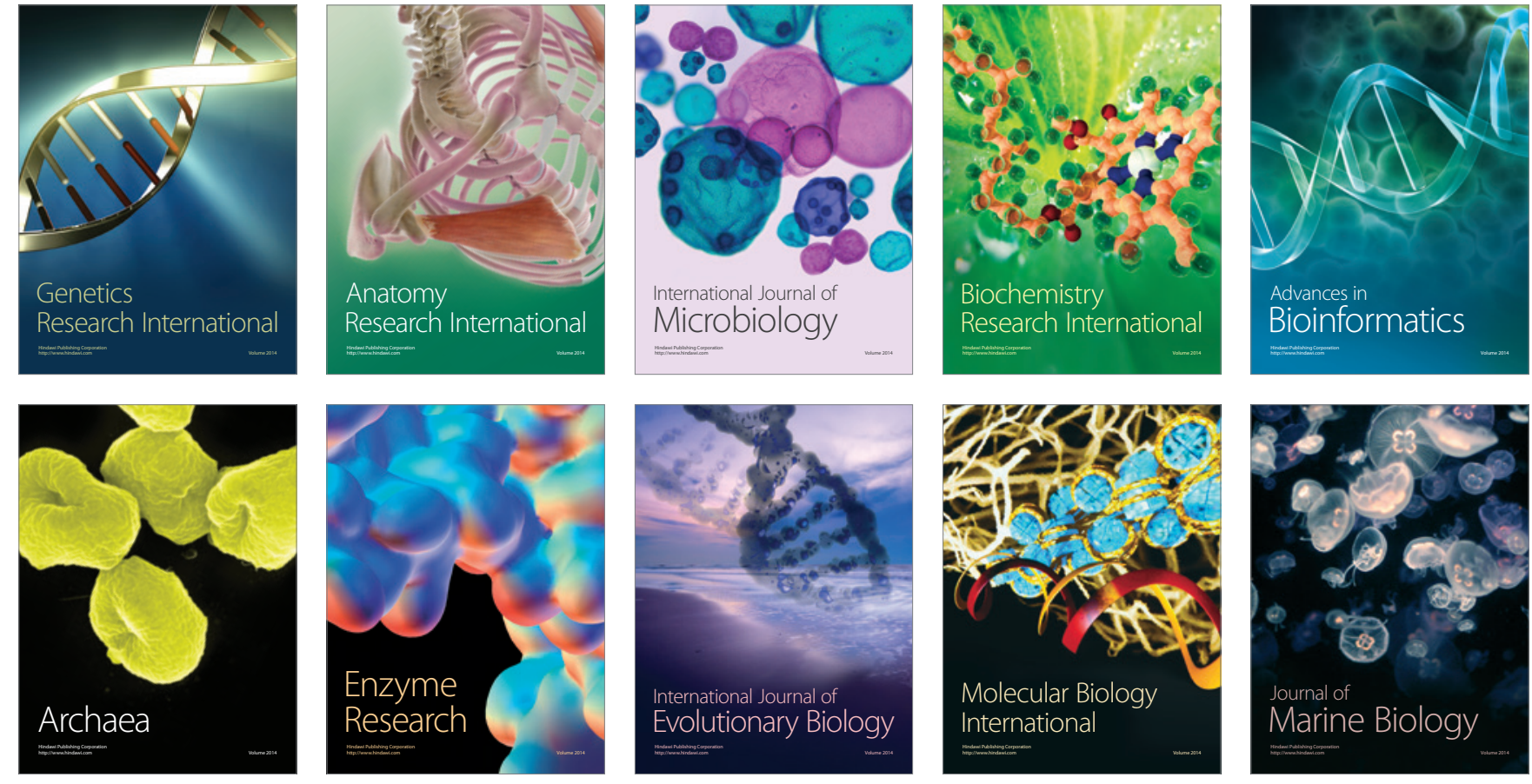